\title{
The Selective Growth of Silicon Nanowires and Their Optical Activation
}

\author{
Lingling Ren, Hongmei Li and Liandi Ma \\ National Institute of Metrology, Beijing, \\ China
}

\section{Introduction}

\subsection{The selective growth of silicon nanowires via vapor-liquid-solid mechanism}

Compared with bulk semiconductors, 1D semiconducting nanowires possess some very unique properties such as quantum confinement effects, surface sensitivity, intrinsically miniaturized dimensions, and low leakage currents which make them attractive as building blocks for functional nanosystems and next generation electronics (Khanal et al., 2007; Andersen et al., 2007; Tilke et al., 2003, as cited in Wu, 2008; Huang et al., 2010). This can be inferred from the sharply increasing number of publications in this field. Figure 1.1 shows the number of publications on nanowires or nanowhiskers by year, determined from a CAS SciFinder search (Wang et al., 2006). Especially for Silicon Nanowires, there are more than 700 articles published in 2008, which is twice the number published in 2005 (Schmidt et al., 2010).

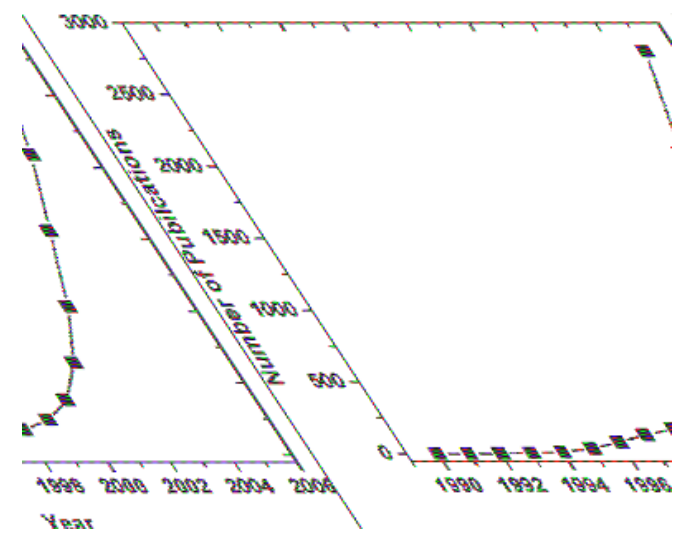

Fig. 1.1 Number of publications on Nanowires or Nanowhiskers by year, determined from CAS SciFinder search.

The earliest silicon wires were produced in the late 1950s as silicon whiskers (Treuting \& Arnold, 1957, as cited in Schmidt et al., 2010). Nowadays, the term whisker has been almost displaced by the term wire and nanowire. Rodlike crystals with a diameter of less than $100 \mathrm{~nm}$ will be referred to as nanowires while the term wire is used to the rodlike crystals of larger diameters (more than 100nm). 


\subsection{Silicon nanowire synthesis based on Vapor-Liquid-Solid (VLS) mechanism 1.2.1 VLS mechanism}

Over the past several years, great efforts have been placed on the bulk synthesis of onedimensional nanoscale materials, and various synthesis methods, such as chemical vapor deposition (CVD) (Amelinckx et al., 1994, as cited in Huang et al., 2010), arc discharge, laser ablation (Thess et al., 1994; Morales \& Lieber, 1998; Yu et al., 1998a; Yudasaka et al., 1997, as cited in Huang et al., 2010), template-assisted growth (Dai et al., 1995; Han et al. 1997a, 1997b, 1998, 1999; Zhang et al., 2000, 2001, as cited in Huang et al., 2010), physical evaporation (PE) (Yu et al., 1997b; Zhang et al., 1999; Zhang et al., 2000, as cited in Huang et al., 2010) and lithography (Giovine et al., 2001, as cited in Huang et al., 2010) have been exploited. The most prominent method for silicon nanowire synthesis is the VLS growth mechanism, which is firstly proposed in March 1964 by Wagner and Ellis.

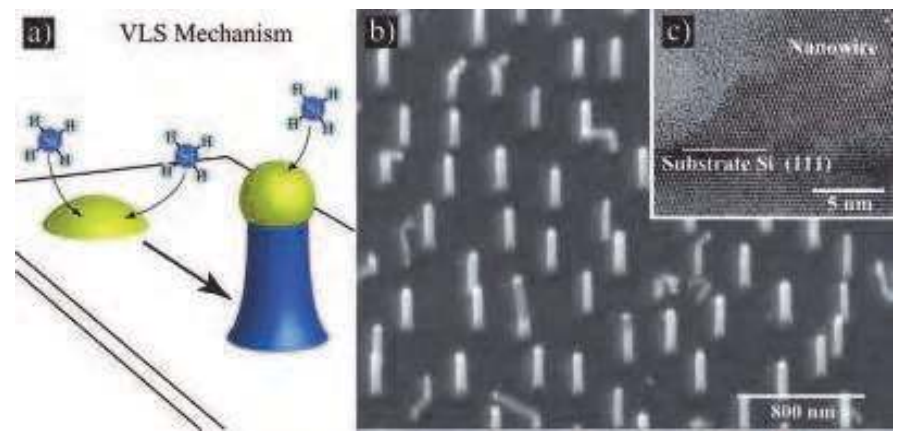

Fig. 1.2 (a) Schematics of the vapor-liquid-solid growth mechanism. (b) Scanning electron micrograph of epitaxially grown Si nanowires on Si <111>. (c) Transmission electron micrograph of the interface region between Si nanowire and substrate. Note the epitaxy and the curved shape of the nanowire flank.

The name VLS mechanism reflects the pathway of $\mathrm{Si}$, which coming from the vapor phase diffuses through the liquid droplet and ends up as a solid Si wire. The VLS mechanism represents the core of silicon wire research, though it does not only work for silicon wire but also for a much broader range of wire materials, such as Ge (Wang et al., 2006) and other IIIVnanowires (Mandl et al., 2011). The VLS growth process can be summarized in the following four steps (Givargizov, 1975, as cited in Schmidt et al., 2010): (1) mass transport of $\mathrm{SiH}_{4}$ from the gas phase to the Au surface; (2) reaction of $\mathrm{SiH}_{4}$ on the Au surface; (3) diffusion of Si through the Au-Si eutectic liquid phase; (4) crystallization of Si from the supersaturated Au-Si eutectic liquid. The VLS mechanism can best be explained on the basis of Au catalyzed $\mathrm{Si}$ wire growth on silicon substrates by means of chemical vapor deposition (CVD) using a gaseous silicon precursor such as silane. Different metal-Si alloy system posses characteristic phase diagrams, which will be elaborated in section 1.2.1.1. The Au-Si binary phase diagram possesses a melting point of the Au-Si alloy strongly depends on composition. If heating $\mathrm{Au}$ in the presence of a sufficient amount of $\mathrm{Si}$, considering e.g. a $\mathrm{Au}$ film on a Si substrate, to temperatures above $363{ }^{\circ} \mathrm{C}$, the melting point of Au-Si alloy of 19 atom \% Si and 81 atom \% Au, will result in the formation of liquid Au-Si alloy droplets as schematically depicted in Figure 1.2a. When a gaseous silicon precursor such as silane, $\mathrm{SiH}_{4}$ covered these Au-Si alloy droplets, the $\mathrm{SiH}_{4}$ will be catalyzed to solid $\mathrm{Si}$ in the droplet 
interface. A continuous supply silicon precursor leads Si consequently to the growth of wires with a Au-Si droplet at their tip. Figure 1.2b is an example of Au-catalyzed $\mathrm{Si}$ nanowires grown homoepitaxially on a $<111>$ substrate via the VLS-mechanism and Figure $1.2 \mathrm{c}$ is the transmission electron micrograph proves the epitaxial relation between nanowire and substrate (Schmidt, 2005, as cited in Schmidt et al., 2010).

As discussed above, the VLS nanowire growth mechanism is merely deduced from the fact that these nanowires generally have alloy droplets on their tips, while the direct evidence, however, is still lacking. A better understanding of the nanowire growth process in the vapor phase is necessary to pin down the growth mechanism and to be able to rationally control their compositions, sizes, crystal structures, and growth directions. P. Yang group (Wu et al., 2001) reported the real-time observation of semiconductor nanowire growth in an in-situ high temperature transmission electron microscope (TEM).
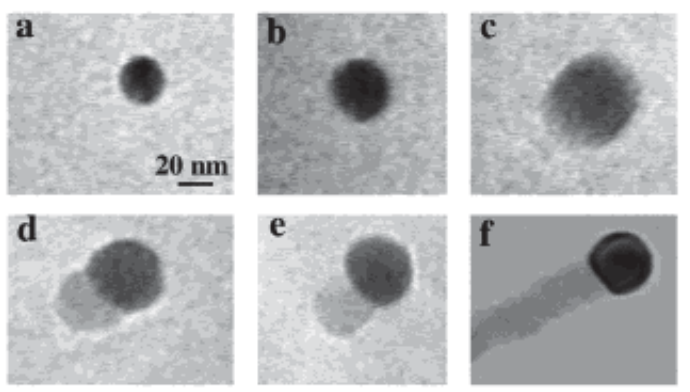

Fig. 1.3 In situ TEM images recorded during the process of nanowire growth. (a) Au nanoclusters in solid state at $500^{\circ} \mathrm{C}$; (b) alloying initiates at $800^{\circ} \mathrm{C}$, at this stage Au exists in mostly solid state; (c) liquid Au/Ge alloy; (d) the nucleation of Ge nanocrystal on the alloy surface; (e)-(f) Ge nanocrystal elongates with further Ge condensation and eventually a wire forms. (Wu et al., 2001)

Figure 1.3a-f shows a sequence of TEM images during the growth of a Ge nanowire in situ. This real-time observation of the nanowire growth directly mirrors the proposed VLS mechanism in Figure 1.4a. We have examined over 50 individual Au clusters during the in situ catalytic nanowire growth. In general, three stages (I-III) could be clearly identified.

i. Alloying process (Figure 1.3a-c). Au clusters remain in the solid state up to our maximum experimental temperature $900{ }^{\circ} \mathrm{C}$ if there is no $\mathrm{Ge}$ vapor condensation. This is confirmed by selected area electron diffraction on the pure Au clusters. With increasing amount of Ge vapor condensation and dissolution, Ge and Au form an alloy and liquefy. The volume of the alloy droplets increases, and the elemental contrast decreases (due to dilution of the heavy metal Au with the lighter element $\mathrm{Ge}$ ) while the alloy composition crosses sequentially, from left to right, a biphasic region (solid Au and $\mathrm{Au} / \mathrm{Ge}$ liquid alloy) and a singlephase region (liquid). This alloying process can be depicted as an isothermal line in the Au-Ge phase diagram (Figure 1.4b).

ii. Nucleation (Figure 1.3d,e). Once the composition of the alloy crosses the second liquidus line, it enters another biphasic region (Au/Ge alloy and Ge crystal). This is where nanowire nucleation starts. Knowing the alloy volume change, we estimate that the nucleation generally occurs at Ge weight percentage of $50-60 \%$. This value differs from the composition calculated from the equilibrium phase diagram which indicates the 
first precipitation of Ge crystal should occur at $40 \%$ Ge (weight) and $800^{\circ} \mathrm{C}$. This difference indicates that the nucleation indeed occurs in a supersaturated alloy liquid.

iii. Axial growth (Figure 1.3d-f). Once the Ge nanocrystal nucleates at the liquid/solid interface, further condensation/ dissolution of Ge vapor into the system will increase the amount of Ge crystal precipitation from the alloy. This can be readily accounted for, using the famous lever rule of phase diagram. The incoming Ge species prefer to diffuse to and condense at the existing solid/liquid interface, primarily due to the fact that less energy will be involved with the crystal step growth as compared with secondary nucleation events in a finite volume. Consequently, secondary nucleation events are efficiently suppressed, and no new solid/liquid interface will be created. The existing interface will then be pushed forward (or backward) to form a nanowire (Figures 1.3f, 1.4b). After the system cools, the alloy droplets solidify on the nanowire tips. Their compositions were analyzed with energy-dispersive X-ray spectroscopy (EDAX), and it was found that the weight percentage of Ge matches qualitatively well with the estimated alloy composition at which first Ge nanocrystal nucleates.

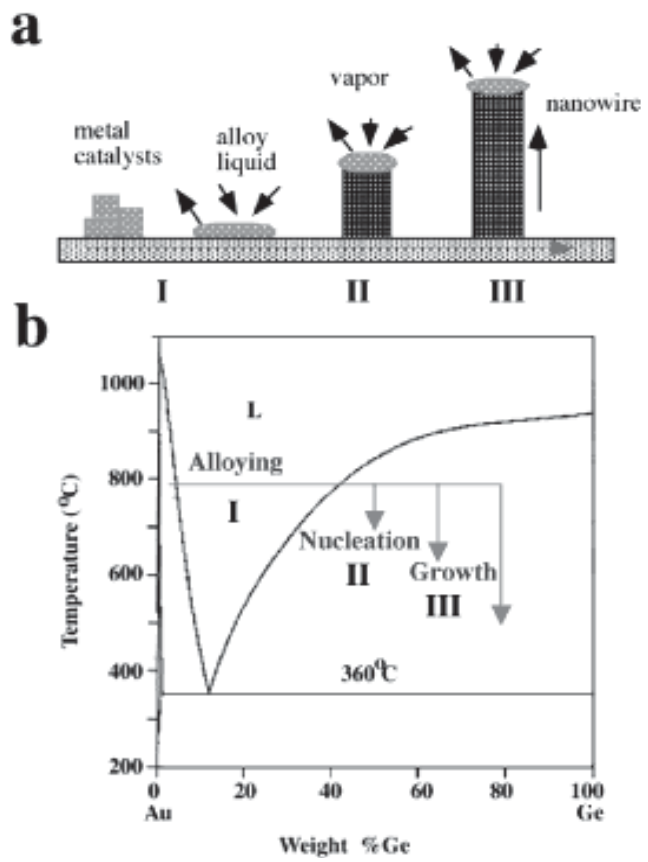

Fig. 1.4 (a) Schematic illustration of vapor-liquid-solid nanowire growth mechanism including three stages (I) alloying, (II) nucleation, and (III) axial growth. The three stages are projected onto the conventional Au-Ge binary phase diagram (b) to show the compositional and phase evolution during the nanowire growth process. (Wu et al., 2001)

The direct observation of nanowire growth unambiguously confirms the validity of vaporliquid-solid crystal growth mechanism at the nanometer scale and should allow us to rationally control the nanowire growth which is critical for their potential implementation into the nanoscale electronic and optoelectronic devices. 


\subsubsection{Phase diagrams of different catalyst-Si alloy system}

The most remarkable feature of the VLS growth mechanism, however, is its universality. VLS growth works well for a multitude of catalyst and wire materials and, regarding Si wire growth, over a size range of at least 5 orders of magnitude; from wire diameters of just a few nanometers up to several hundred micrometers.

The characteristic of VLS mechanism is the application of metal catalyst, which is generally selected by phase diagrams. Figure 1.5 is showing phase diagrams of different metal-Si alloy system. To formulate the requirement on the catalyst-Si binary phase diagram in a more abstract way, Si wire growth requires a nonhorizontal phase boundary over which one can push the catalyst-Si system to enforce the precipitation of a $\mathrm{Si}$ rich solid. The catalyst materials are classified into three different categories by the phase diagrams of metal-Si system: Type-A, Type-B, Type-C (Bootsma \& Gassen, 1971, as cited in Schmidt et al., 2010), as shown in figure 1.6.
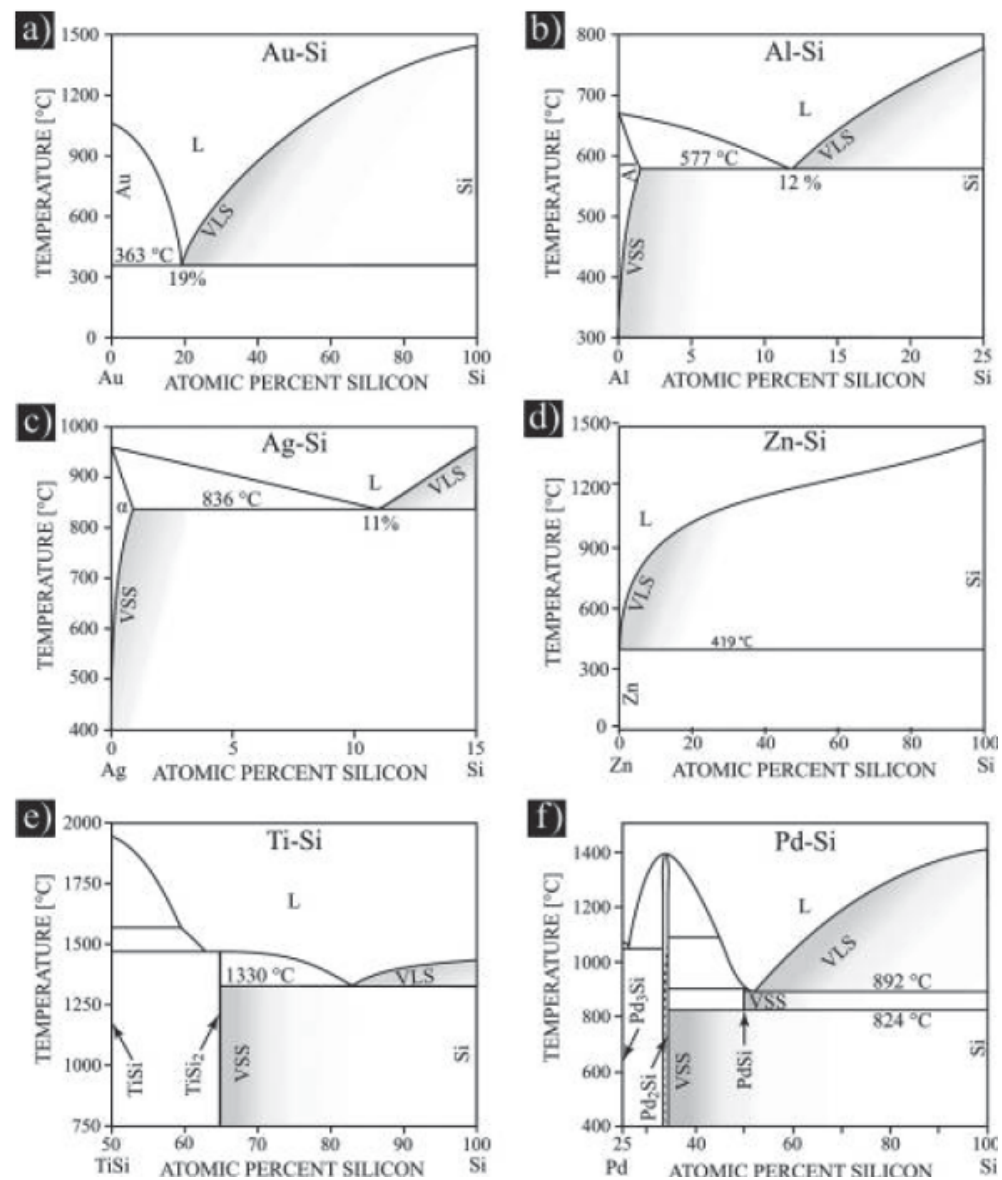

Fig. 1.5 Schematic phase diagrams of different metal-Si systems. (a) Au-Si, (b) Al-Si, (c) AgSi, (d) Zn-Si, (e) Ti-Si, (f) Pd-Si (Weber, 2002, as cited in Schmidt et al., 2010). 
Type-A catalysts are the Au-like metals. Their phase diagram is of the simple eutectic type; that is, it is dominated by a single eutectic point. This eutectic point is located at a $\mathrm{Si}$ composition of more than 10 atom \% Si. Furthermore, type-A catalysts do not possess any metal-silicide phases. There are only three type- $\mathrm{A}$ metals: $\mathrm{Al}, \mathrm{Ag}$, and $\mathrm{Au}$.

$\mathrm{Au}$ is the most convenient and effective catalyst due to its nontoxicity, chemical stability and availability. Au is available not only by evaporation, but by Au colloid nanoparticles. And $\mathrm{Au}$ doesn't oxidize in air to make an in situ deposition unnecessary, which is a decisive advantage for the pregrowth sample preparation. The Au-Si phase diagram is of the simple eutectic type, with its dominant feature being a eutectic point at a composition of about 19 atom $\% \mathrm{Si}$, indicating that $\mathrm{Si}$ likes to mix with $\mathrm{Au}$. The eutectic temperature is $363{ }^{\circ} \mathrm{C}$, a quite remarkable reduction of melting temperature, which is $700 \mathrm{~K}$ lower than the melting point of pure $\mathrm{Au}$ and about $1050 \mathrm{~K}$ below the melting point of pure Si. The phase within the Vshaped region, visible in Figure 1.5a, is the liquid phase, the actual composition of which depends on the amount of $\mathrm{Si}$ supplied. For Au-Si alloy droplets on a Si substrate, $\mathrm{Si}$ is abundant, and the composition of such Au-Si droplets is therefore given by the position of the liquidus line on the Si side, i.e. the phase boundary on the right-hand side (rhs) of the liquid phase. If such Au-Si droplets on a Si substrate, held at temperatures above the eutectic temperature, are exposed to a $\mathrm{Si}$ precursor such as silane, $\mathrm{SiH}_{4}$, silane molecules will crack at the surface of the droplets, thereby supplying additional $\mathrm{Si}$ to the droplet. This additional Si supply causes an increase of the Si concentration in the droplet to a value greater than the equilibrium concentration. Considering the Au-Si phase diagram shown in Figure 1.5a, this means that, by switching on the silane, the Au-Si droplet system is pushed over the liquidus line; and the only way for the droplet to reduce the Si concentration is to precipitate a Si-rich solid. In general, the composition of such a Si-rich solid would be given by the nearest phase boundary on the Si side of the liquidus. Consequently, the droplet precipitates $\mathrm{Si}$, which with time results in the growth of a wire (Schmidt et al., 2010).

The drawback for $\mathrm{Au}$ is the contamination of the nanowires (Allen et al., 2008; Perea et al., 2006; Shchetinin et al., 1991) in the semiconductor industry. Because it is associated with deep-level defects in $\mathrm{Si}$, leading to strongly enhanced carrier recombination. Metal impurities in semiconductors are generally known to affect the charge carrier lifetimes by facilitating charge carrier recombination. The recombination rate critically depends on the energy difference between the impurity level or levels and the band gap middle; the closer the impurity level is to the band gap middle, the more efficient it is as a recombination center. The use of metals with impurity levels close to the band gap middle, so-called deep levels, is therefore to be avoided.

$\mathrm{Al}$, another Type-A catalyst, shows the closest similarity of Al-Si binary phase diagram (see Figure 1.5b) with Au-Si, excluding that the eutectic point of the Al-Si system is located at a higher temperature $\left(577^{\circ} \mathrm{C}\right)$ and at a slightly lower Si concentration (12 atom\%). So Al could catalyze the VLS growth of Si nanowires undoubtly. Osada et al. (Osada et al., 1979, as cited in Schmidt et al., 2010) demonstrated Al catalyzed VLS growth of crystalline Si wires in a $\mathrm{CVD}$ process using silane and applying temperatures of $580-700^{\circ} \mathrm{C}$. Compared with $\mathrm{Au}, \mathrm{Al}$ catalyst shows the great advantage that $\mathrm{Al}$ does not create deep level defects. The major drawback of the use of $\mathrm{Al}$, however, is its oxygen sensitivity. Oxidation of the $\mathrm{Al}$ catalyst particle has to be prevented during the whole processing sequence, which clearly limits the usability of Al. 
Silver is the second nongold, type-A catalyst. The Ag-Si system (see Figure 1.5c) possesses a single eutectic point (at 11 atom \% Si and $836{ }^{\circ} \mathrm{C}$ ) (Weber, 2002, as cited in Schmidt et al., 2010). Due to the high eutectic temperature, high process temperatures at around $1000{ }^{\circ} \mathrm{C}$ are required for Ag-catalyzed VLS growth of Si wires. So the high process temperature becomes the disadvantage of Ag catalyst, because the Ag catalyst did not evaporate completely under these conditions, as the vapor pressure of $\mathrm{Ag}$ reaches a value close to $10^{-2}$ mbar at $1000{ }^{\circ} \mathrm{C}$, which is about 3 orders of magnitude larger than that of Au (Geiger et al., 1987, as cited in Schmidt et al., 2010 ).

Type-B catalysts are the low Si solubility metals. Their phase diagrams also show a single dominant eutectic point but no silicide phases. In contrast to the type-A catalysts, the eutectic point is located at much lower Si concentrations, less than 1 atom \% Si. Typical type$\mathrm{B}$ catalysts are In, $\mathrm{Ga}$, or $\mathrm{Zn}$. The $\mathrm{Zn}$-Si binary phase diagram is dominated by a single eutectic point at $420^{\circ} \mathrm{C}$ and 0.02 atom \% Si, shown in Figure 1.5d, and despite its high vapor pressure of $0.2 \mathrm{mbar}$ at $420^{\circ} \mathrm{C}, \mathrm{Zn}$ has proven to be an effective catalyst material for VLS growth (Chung et al., 2000). However, the impurity levels of $\mathrm{Zn}$ in $\mathrm{Si}$ are basically as detrimental as those of $\mathrm{Au}$ in the view of the electronic properties. The only advantage of using $\mathrm{Zn}$ is that a potential $\mathrm{Zn}$ contamination of wafers or equipment can be removed more easily than a potential Au contamination.

Ga or In as catalyst of VLS growth appears to be much more attractive than that of Zn from a vapor pressure point of view. At $500{ }^{\circ} \mathrm{C}$, the vapor pressure of In is below $10^{-7} \mathrm{mbar}$, and the vapor pressure of $\mathrm{Ga}$ is even lower: 10-10 mbar (Schmidt et al., 2010). Moreover, In and Ga would also be attractive from an electronics point, as both would induce a p-type doping of the wires. In terms of phase diagrams, $\mathrm{Ga}$ and In show great similarities. The Si concentrations at the eutectic point (smaller 0.01 atom \%) as well as the eutectic temperatures $\left(\mathrm{Ga}, 30^{\circ} \mathrm{C}\right.$; In, $\left.156^{\circ} \mathrm{C}\right)$ are very low in both cases, and any reasonable $\mathrm{CVD}$ growth temperatures will be way above the respective eutectic temperature. Therefore In or Ga can be expected to produce similar Si nanowire results (Givargizov \& Sheftal, 1971, as cited in Schmidt et al., 2010).

Type-C catalysts are the silicide forming metals. Their phase diagram indicates the presence of one or more silicide phases. In addition, the lowest eutectic temperature is higher than $800^{\circ} \mathrm{C}$. Typical type-C catalysts are $\mathrm{Cu}, \mathrm{Pt}$, or Ti. Here is showing based on Ti catalyst. Figure 1.5e schematically depicts the Si-rich half of the Ti-Si phase diagram. As indicated therein, Ti-Si possesses a eutectic point at $1330^{\circ} \mathrm{C}$ adjoining the pure $\mathrm{Si}$ side of the phase diagram, whose liquidus can be used for Si wire growth via the VLS mechanism. At growth temperatures below $1330^{\circ} \mathrm{C}$, growth should theoretically proceed via the phase that at this temperature is neighboring the pure $\mathrm{Si}$ side. As one can see in Figure 1.5e, this would be $\mathrm{TiSi}_{2}$. Considering growth at $1000^{\circ} \mathrm{C}$ and starting from a Ti particle, this Ti particle will first transform into $\mathrm{Ti}_{5} \mathrm{Si}_{3}$ and then into $\mathrm{Ti}_{5} \mathrm{Si}_{4}$, which becomes $\mathrm{TiSi}$, which will finally transform into $\mathrm{TiSi}_{2}$. Only once this transformation process is completed can Si wire growth start.

To explain the one-dimensional growth of Si nanowires prepared via VLS, the generation of invisible charged nanoparticles during VLS is experimentally confirmed. In an effort to confirm whether charged silicon nanoparticles were also generated during the synthesis of Si nanowires by VLS, a differential mobility analyzer (DMA) combined with a Faraday cup electrometer (FCE) was connected to an atmospheric-pressure CVD reactor under typical conditions for Si nanowire growth, as shown in Figure 1.7 (Kim et al., 2010). 


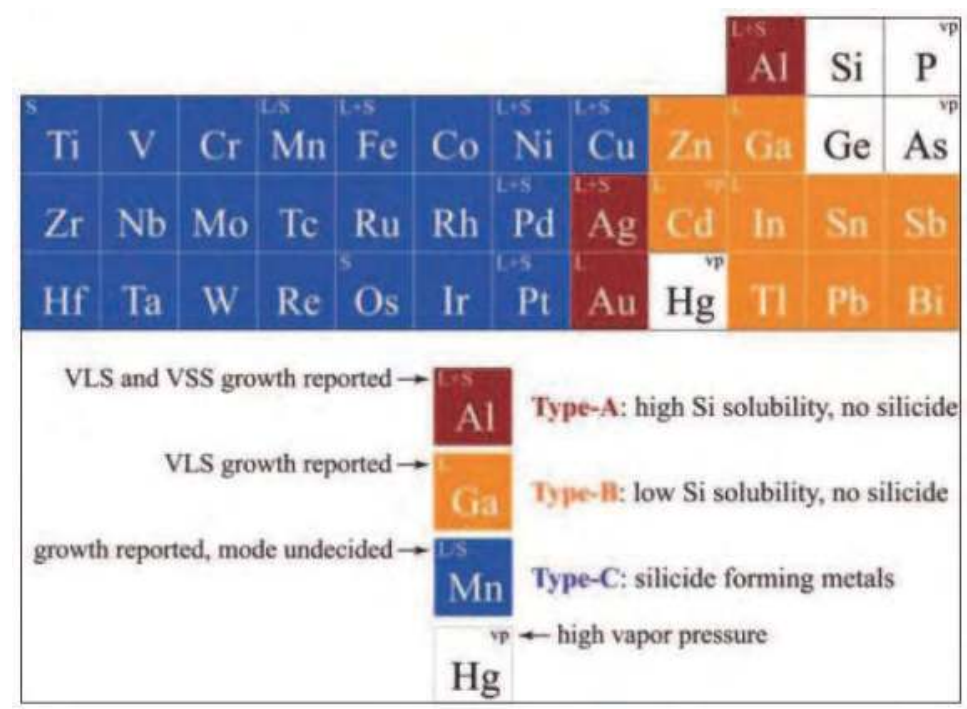

Fig. 1.6 Periodic table with potential catalyst metals classified according to their phase diagram. Type-A: phase diagram dominated by a eutectic point at a Si concentration $>10 \%$; no metal-silicide phase present. Type-B: phase diagram dominated by a eutectic point at a Si concentration $<1 \%$; no metal-silicide phases present. Type-C: phase diagram with one or more metal-silicide phases; eutectic points located at temperatures above $800^{\circ} \mathrm{C}$. Elements marked with superscript ion have a vapor pressure of more than $0.01 \mathrm{mbar}$ at $300^{\circ} \mathrm{C}$ (Bootsma \& Gassen, 1971, as cited in Schmidt et al., 2010).

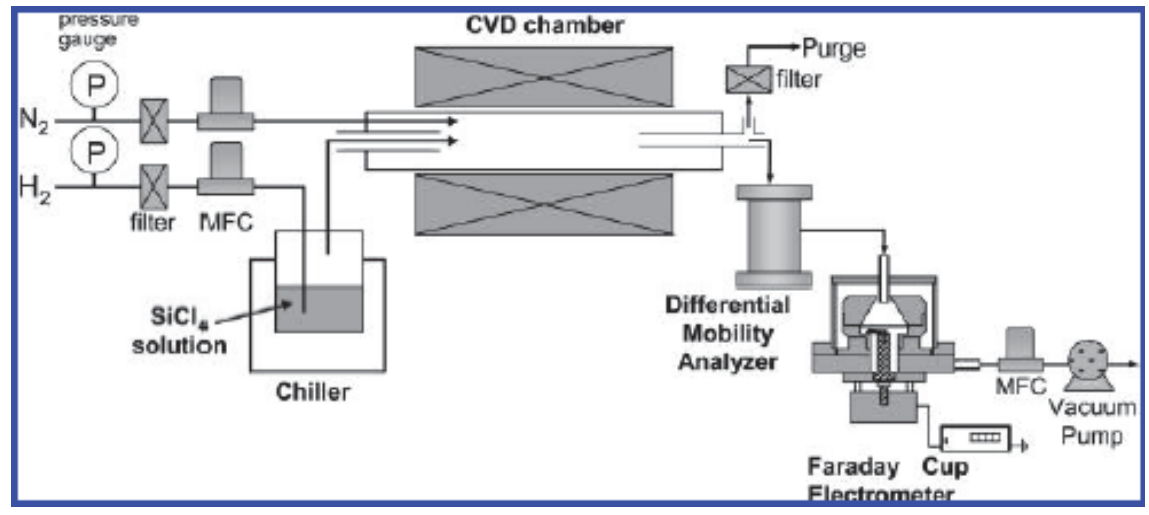

Fig. 1.7 Schematic of experimental setup for the measurement of charged nanoparticles generated during theVLS process (Kim et al., 2010).

To investigate the effect of the reactor temperature on the deposition of Si nanowires and on the formation of nanoparticles in the gas phase, the reactor temperature was varied from 900 to $1000{ }^{\circ} \mathrm{C}$ at a $\mathrm{SiCl}_{4} / \mathrm{H}_{2}$ molar ratio of 0.1 and a hydrogen flow rate of $5 \mathrm{sccm}$, with the total flow rate of nitrogen and hydrogen fixed at $1000 \mathrm{sccm}$, and in situ measurements of charged 
nanoparticles were carried out using a DMA-FCE system. The results show that as the reactor temperature was increased, Si nanowire growth is enhanced with increasing reactor temperatures within the examined temperature range, and the size distribution of both positively and negatively charged nanoparticles shifted to smaller particle sizes and the number concentration of charged nanoparticles increased. At reactor temperatures above $900^{\circ} \mathrm{C}$, the number concentration of charged nanoparticles smaller than $\sim 30 \mathrm{~nm}$ increased drastically. These results indicate that the decomposition of $\mathrm{SiCl}_{4}$ increased with increasing reactor temperature. Thus, nucleation and charging of nanoparticles in the gas phase are enhanced with increasing reactor temperature due to enhanced thermal decomposition of $\mathrm{SiCl}_{4}$.

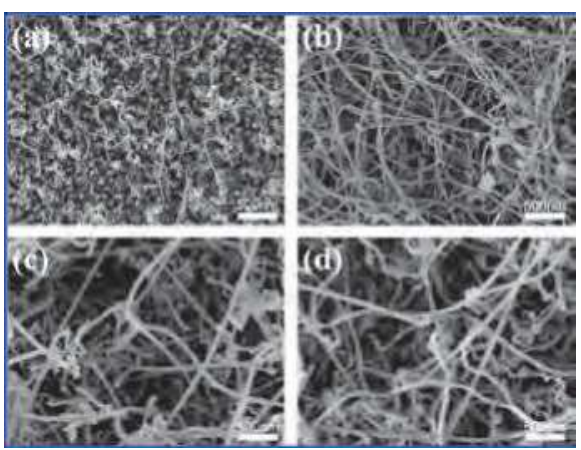

Fig. 1.8 FESEM images of $\mathrm{Si}$ nanowires at $\mathrm{SiCl}_{4} / \mathrm{H}_{2}$ molar ratios of (a) 0.05, (b) 0.1, (C) 0.15, and (d) 0.2 at a hydrogen flow rate of $5 \mathrm{sccm}$ and a reactor temperature of $975^{\circ} \mathrm{C}$ (the scale bar is $500 \mathrm{~nm}$ ) (Kim et al., 2010).

To examine the effect of the molar ratio of $\mathrm{SiCl}_{4} / \mathrm{H}_{2}$ on both $\mathrm{Si}$ nanowire growth and the size distribution of charged nanoparticles, the molar ratio of $\mathrm{SiCl}_{4} / \mathrm{H}_{2}$ was varied at a fixed hydrogen flow rate of $5 \mathrm{sccm}$ and a reactor temperature of $975^{\circ} \mathrm{C}$. Figure 1.8 shows the FESEM images of nanowires formed at different molar ratios of $\mathrm{SiCl}_{4} / \mathrm{H}_{2}$. As the ratio of $\mathrm{SiCl}_{4} / \mathrm{H}_{2}$ was increased, both the diameter and the length of the nanowires increased. As the ratio of $\mathrm{SiCl}_{4} / \mathrm{H}_{2}$ was increased from 0.05 to 0.1 , the diameter increased from 24 to $35 \mathrm{~nm}$, and the length and the density of the nanowires were also markedly increased. As the ratio $\mathrm{SiCl}_{4} / \mathrm{H}_{2}$ was further increased to 0.15 and 0.20 , the diameter drastically increased to 61 and $65 \mathrm{~nm}$, respectively. This result indicates that the ratio of $\mathrm{SiCl}_{4} / \mathrm{H}_{2}$ is an important parameter controlling the diameter and length of Si nanowires. Therefore, the size of the gold nanoparticles is not the only parameter that determines the diameter of the Si nanowires that grow on them.

Figure 1.9 shows the particle size distribution of positively (Figure 9a) and negatively (Figure $9 \mathrm{~b}$ ) charged nanoparticles generated at various $\mathrm{SiCl}_{4} / \mathrm{H}_{2}$ ratios. The size distribution of positively and negatively charged nanoparticles generated at a $\mathrm{SiCl}_{4} / \mathrm{H}_{2}$ ratio of 0.05 has a peak at $14.6 \mathrm{~nm}$. As the ratio of $\mathrm{SiCl}_{4} / \mathrm{H}_{2}$ increased, the size distribution of both positively and negatively charged nanoparticles shifted to larger particle sizes and the number concentration of charged nanoparticles increased drastically. However, the peak diameter did not change considerably at a $\mathrm{SiCl}_{4} / \mathrm{H}_{2}$ ratio higher than 0.1 . These results show that the ratio of $\mathrm{SiCl}_{4} / \mathrm{H}_{2}$ not only affects the growth behavior of $\mathrm{Si}$ nanowires but also affects the size distribution of charged nanoparticles. 


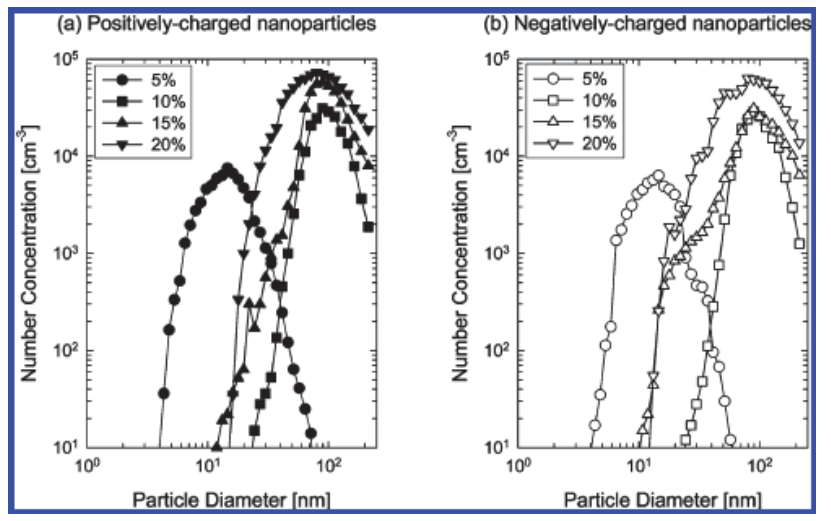

Fig. 1.9 Size distribution of (a) positively and (b) negatively charged nanoparticles at various molar ratios of $\mathrm{SiCl}_{4} / \mathrm{H}_{2}$ at a hydrogen flow rate of $5 \mathrm{sccm}$ and a reactor temperature of $975^{\circ} \mathrm{C}$ (Kim et al., 2010).

Similiarly, the hydrogen flow rate has a sensitive effect on the generation of charged nanoparticles as well as the growth behavior of Si nanowires. As the hydrogen flow rate was increased from 5 to $10 \mathrm{sccm}$, the number concentration of charged nanoparticles increased, but it decreased at the hydrogen flow rate of $15 \mathrm{sccm}$. Especially at a hydrogen flow rate of $15 \mathrm{sccm}$, where Si nanowires did not grow, charged nanoparticles below $40 \mathrm{~nm}$ were not detected.

The formation mechanism of charged silicon nanoparticles generated during $\mathrm{Si}$ nanowire synthesis by VLS could be deduced that gas phase nuclei of silicon would be formed first and then these nuclei undergo surface ionization on any surface, such as thevquartz tube of the reactor (Kim et al., 2009b). The surface ionization of gas phase nuclei is very similar to the electrostatic charging or triboelectric charging that is experienced commonly in everyday life. The electrostatic charging shows that charging can occur even at room temperature. it is more probable that the charged nanoparticles, instead of individual atoms or molecules, produced in the VLS process, should interact with the catalytic gold particles to produce the Si nanowires. The electrostatic attraction between the charged nanoparticles and the conducting gold particles would be much stronger than that between the charged nanoparticles and the insulating native oxide of the silicon substrate. The nanoparticles carried by the gas flow have difficulty in landing on a surface because of the levitation force: the gas flow velocity is zero on the surface and increases away from the surface. For charged nanoparticles to land on any surface, the electrostatic attraction between charged nanoparticles and the surface should overcome this levitation force. It appears that the electrostatic attraction between charged nanoparticles and the conducting gold particles is larger than the levitation force, whereas the electrostatic attraction between charged nanoparticles and the native silicon oxide of the substrate or the silicon surface of nanowires is less than the levitation force. This might be why charged nanoparticles land preferentially on the conducting gold particles, leading to nanowire growth. When the rod-shaped silicon is formed with a gold nanoparticle at its tip, the charged silicon nanoparticles would be attracted to the gold tip more preferentially than to the side of the silicon rod, considering that the charged nanoparticles should have higher electrostatic attraction energy with the conducting gold nanoparticles than with the side of the semiconducting silicon rod. 


\subsubsection{The selective growth of SiNWs based on VLS mechanism}

\subsubsection{SiNW diameter controlling via VLS mechanism}

Precise control of the SiNW diameter strongly affects the electrical and optical properties of the nanowires (Brus, 1994). The diameter of each Si nanowire is largely determinded by the size of the catalyst particle and growth conditions. In general, Au colloids are used to define the diameter and position of the SiNWs. Au colloids are ideal seeds for controlling the SiNW diameter: They act as the seeding metal for nanowire growth by the VLS process, and Au colloids may be synthesized or obtained commercially with relatively narrow size distributions. Since each colloid seeds the growth for one nanowire, aligned nanowires can be grown with narrow size distributions approaching those of the seed particles. Hence, by seeding wire growth with colloids of different average size, the average diameter of the SiNW arrays could be precisely controlled (Cui et al., 2001; Wu et al., 2004).

Using a thin polyelectrolyte layer, gold colloids are electrostatically attracted to and immobilized on the substrate to act as seeds for Si nanowires grown using the VLS-CVD method. The diameter of the colloids precisely controls the nanowire diameter. The colloid solution concentration controls the density of growth. Microcontact printing of the polyelectrolyte layer confines wire growth to patterned regions (Hochbaum et al., 2005). As seen in Figure 1.10b, d, and f. Size distributions of both colloids and nanowires were determined from TEM micrographs. SiNWs grown from Au colloids of 50 (56 \pm 5.0 ), 30 (30 $\pm 3.3)$, and $20(20 \pm 2.1) \mathrm{nm}$ diameters were $93 \pm 7.4,43 \pm 4.4$, and $39 \pm 3.7 \mathrm{~nm}$ in diameter, respectively (Hochbaum et al., 2005).
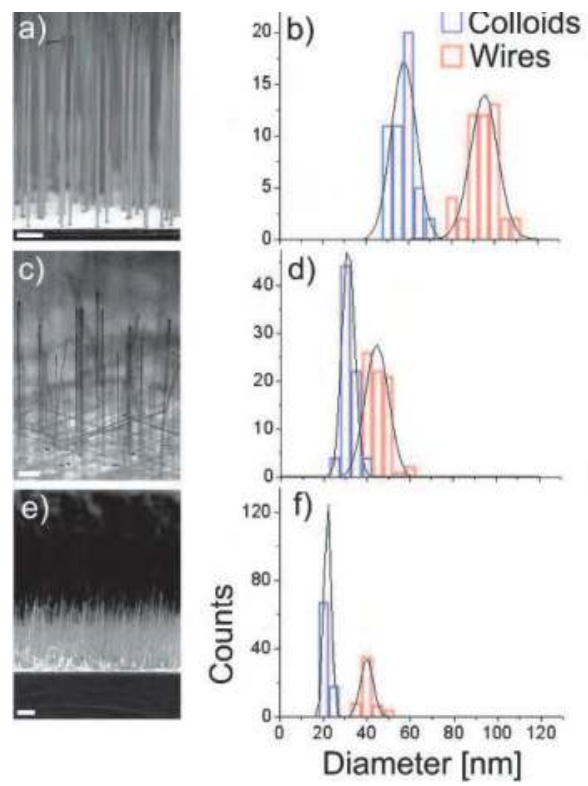

Fig. 1.10 (a, c, e) Cross-sectional images of nanowire samples grown from 50, 30, and $20 \mathrm{~nm}$ (nominally) Au colloids, respectively. Scale bars are $1 \mu \mathrm{m}$. (b, d, f) Size distributions of $\mathrm{Au}$ colloids and resulting SiNW diameters. (g) High-resolution transmission electron microscopy image of a single crystalline Si nanowire. Scale bar is $3 \mathrm{~nm}$ (Hochbaum et al., 2005). 
The density of nanowire growth is also critical to device function. By varying the concentration of the seeding solution (using $50 \mathrm{~nm}$ Au colloids as example here), we were able to control the seeding density on the substrate surface. The graph in Figure 1.11 shows the relationship between nanowire growth density, as determined from SEM images, and dilution of the gold colloid stock solution. Wires were seeded with densities ranging over an order of magnitude, from $\sim 0.1-1.8$ wires $/ \mu \mathrm{m}^{2}$. In general, a good 1-to-1 nanoparticle/ nanowire ratio can be achieved, although it was observed that optimal growth conditions varied slightly with nanowire seeding density.

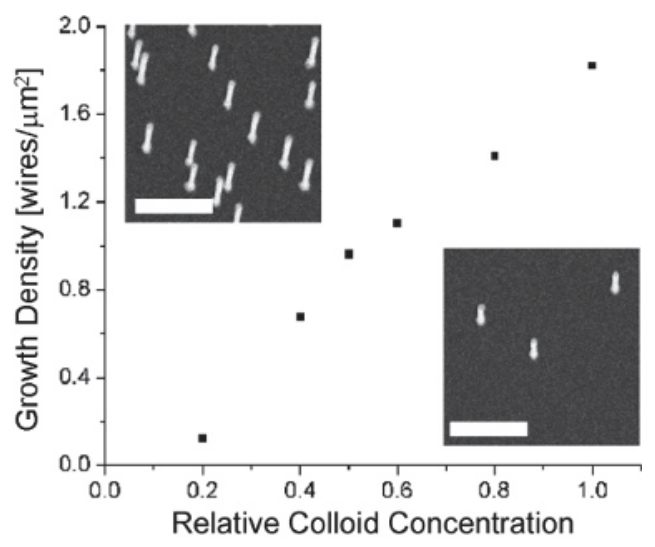

Fig. 1.11 SiNW growth density dependence on the relative concentration of the seeding solution. All colloid solutions were diluted from the same stock solution. Insets show typical nanowire growth at $4 / 5$ (top left) and $2 / 5$ dilution (bottom right). Scale bars are $1 \mu \mathrm{m}$ (Hochbaum et al., 2005).

\subsubsection{Spatial controlling via VLS mechanism}

For both phenomenological studies and the implementation of practical applications of SiNWs, fabrication of regular arrays of $\mathrm{Si}$ wires, with precise control of the crystallographic orientation, dimension, and density will be of great value. For laser interference lithography, the ultimate achievable resolution equals to one-fourth of the laser wavelength (Solak, 2006).To overcome the limitation in achieving reliable diameter reduction by reactive ion etching (RIE) for the smaller dimensions, template-based methods offer access to a wide variety of nanowires with a broad diversity in composition and shape. As template material, most commonly substrates such as track-etched polycarbonate membranes (Azarian et al., 2009), mesoporous silica (Petkov et al., 2007) and porous anodic alumina membranes (Xiang et al., 2008; Gao et al., 2002) are used.

A porous anodic alumina (PAA) is a material characterized by a honeycomb pattern of nanometer-sized pores with uniform diameter and spacin (Masuda \& Fukuda, 1995). The pores are formed during the electrochemical anodization of aluminum under controlled conditions; different self-ordering conditions yield pores of different diameters and spacing (Nielsch et al., 2002). They give easy access to self-organized pores with high aspect ratios and tunable pore sizes (Gao et al. 2002; Masuda \& Fukuda et al., 1995; Krishnan \& Thompson, 2007; Nielsch et al., 2000). These pores are then used as a molding system for the synthesis of the desired nanostructures (Xiang et al., 2010). 


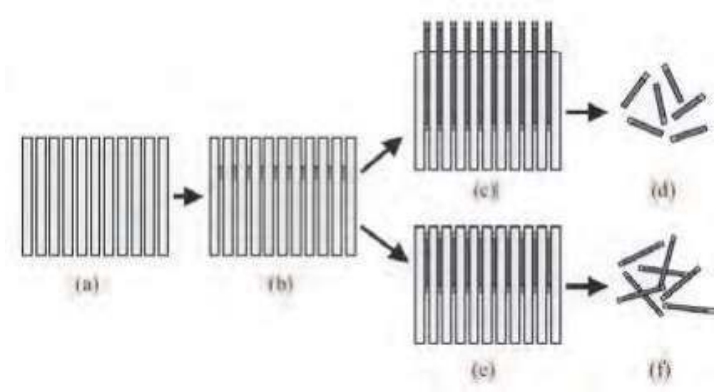

Fig. 1.12 Schematic diagram of the fabrication method used for the PAA template-based growth of SiNWs. (a) Cross-section of PAA, (b) electro-deposition of Au within pores, (c) VLS growth of SiNWs out of membrane surface, (d) SiNW removal by mechanical agitation, (e) VLS growth of SiNWs within membrane, and (f) SiNW removal by wet etching of membrane (Bogart et al., 2005).

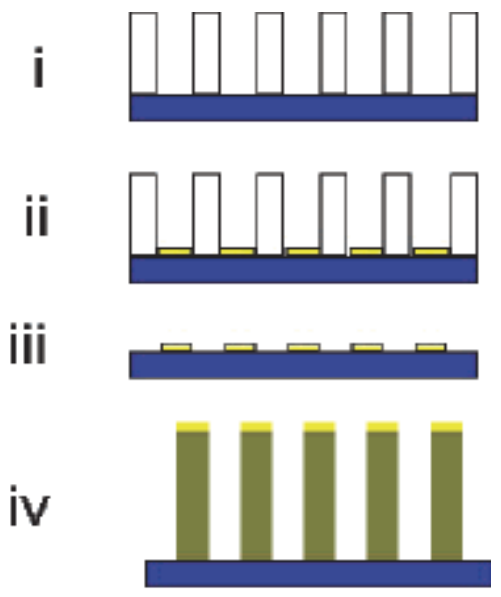

Fig. 1.13 Schematic diagram of the fabrication method used for the PAA template-based growth of SiNWs. (i) Transfer of the PAA mask on Si (111), (ii) evaporation of Au through the PAA pores, (iii) PAA removal, and (iv) growth of SiNWs from the patterned substrate.

The VLS growth of SiNWs inside the pores of an unsupported PAA template using $\mathrm{SiH}_{4}$ as the precursor gas has been completed (Bogart et al., 2005; Lew \& Redwing, 2003; Zhang et al., 2001), as shown in Figure 1.12. Briefly, gold is electro-deposited inside a free-standing PAA membrane, and the Au loaded template is placed inside the VLS growth furnace where SiNWs with uniform diameter are grown inside the pores of the alumina film. Subsequently, the template is dissolved (Bogart et al., 2005). The disadvantage of this process is that produced SiNWs are unsupported. In order to overcome the production of unsupported nanowires, due to the preventing their integration into functional devices (Lombardi et al., 2006), evaporation of Au through the PAA pores have been applied to overcome the dispesrion of SiNWs after removal of PPA membrane, as shown in Figure 1.13 (Lombardi et al., 2006). 
Figure 1.14 shows the ordered pattern of gold nanodots after the thermal evaporation step and PAA mask removal. The size and arrangement of the gold clusters closely match those of the PAA pores. The average diameter of the dots is $53 \mathrm{~nm}$ with a standard deviation of $7.2 \%$. The SiNW density could be controlled by simply changing the acid etch of the PAA film yielding pores up to required diameter while keeping the distance between pores unchanged. As a result, the gold nanoparticle arrays are arranged in a highly ordered configuration reflecting the hexagonal pattern of the nanopores of the PAA mask. SiNWs with controlled dimensions and spacings are grown in a rather inexpensive manner with this approach over large areas $(\sim 7 \mathrm{~mm} \times \sim 7 \mathrm{~mm})$. Additionally, this fabrication method is capable of producing SiNWs with a packing density as high as $6 \times 10^{9} / \mathrm{cm}^{2}$, which could be achieved otherwise only with lithographic techniques, entailing serious limits for mass scale production of these nanomaterials.

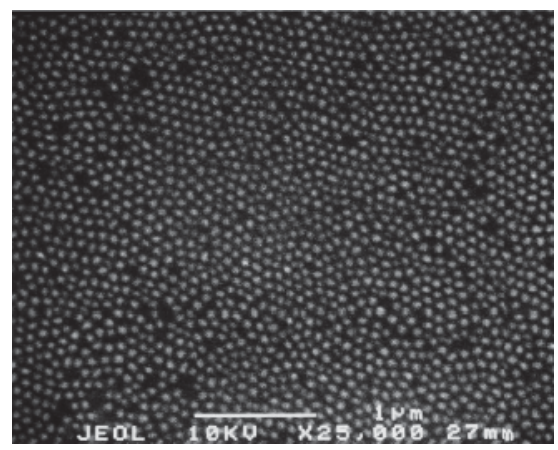

Fig. 1.14 Ordered arrays of Au nanodots evaporated through the nanochannels of the PAA mask. The clusters have an average diameter of $53 \mathrm{~nm}$ and a dot-to-dot distance of $100 \mathrm{~nm}$. The height of the dots is $5 \mathrm{~nm}$.
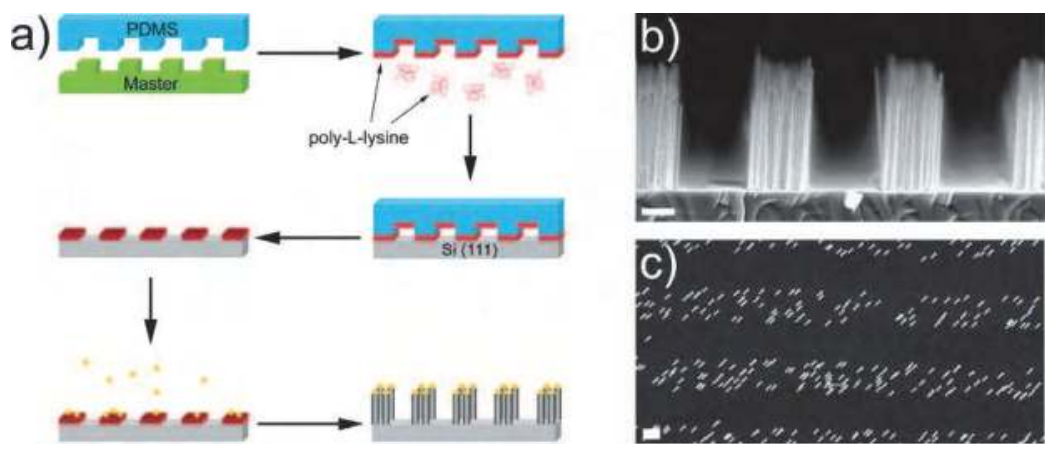

Fig. 1.15 (a) Schematic of PDMS patterning of Au colloids. Briefly, a PDMS stamp is molded to the relief pattern of a photoresist master. After curing the polymer, the stamp is removed from the master and "inked" with a solution of poly-L-lysine. The stamp pattern is transferred to the $\mathrm{Si}$ (111) substrate, which is then immersed in the Au colloid solution. The colloid-patterned substrate is grown using the conventional VLS-CVD synthesis, resulting in a corresponding pattern of SiNW arrays. (b) Cross-sectional SEM image of PDMS patterned SiNW growth, and (c) plane-view SEM image of the same. Scale bars are $1 \mu \mathrm{m}$ (Hochbaum et al., 2005). 
A poly(dimethylsiloxane) (PMDS) stamp was made using a photoresist master of $2 \mu \mathrm{m}$ lines with $2 \mu \mathrm{m}$ separation, and the pattern was transferred to the substrate by previously established techniques (Hochbaum et al., 2005) (Figure 1.15a). The stamp was "inked" with the poly-L-lysine solution by the same method described above for deposition on the $\mathrm{Si}$ substrates. The polymer pattern was transferred to a Si wafer by placing the stamp on the substrate and heating at $70{ }^{\circ} \mathrm{C}$ for $5 \mathrm{~min}$. The patterned substrate was immersed in the 50 $\mathrm{nm} \mathrm{Au}$ colloid solution for a short time, such that colloids only adhered to the polyelectrolyte and not the bare Si. Nanowires were synthesized on these substrates by the same VLS method. The resulting growth, seen in Figure $1.15 \mathrm{~b}$ and $\mathrm{c}$, is strictly confined to the regions of poly-L-lysine deposition. The plane-view SEM image (Figure 15c) shows a small part of the pattern, which is consistent over several square millimeters - the extent of the stamped area that was immersed in the colloid solution. Thus, spatial control over SiNW growth was achieved by patterning regions of seed particles using microcontact printing.

\subsection{Conclusion}

The VLS mechanism is a well established growth technology for SiNWs. Based on the VLS mechanism, the diameter, the density and the special arrays of SiNWs can be well controlled by careful selections of catalysts, the templates and the growth conditions. The future challenge is the controllable growth of SiNWs matching with the devices requirements, such as single SiNW growth in an ordered place, the uncontaminated SiNWs.

\section{Optical activation of Si and Ge nanowires codoping with Er rare earth by sol-gel methods}

\subsection{Introduction}

The discovery of the strong Stokes shift between absorption and emission in Si nanostructures suggested that emission could be due to an interfacial radiative emission center (Song \& Bao, 1997; Klimov et al., 1998; Iacona et al., 2000, as cited in Priolo et al., 2001). Moreover, the quantum confinement picture and the interfacial state model have been reconciled by demonstrating that a $\mathrm{Si}=\mathrm{O}$ double bond introduces size-dependent levels (both for electrons and for holes) within the gap (Wolkin et al., 1999). According to this picture it is the radiative recombination of this electron-hole pair trapped at the $\mathrm{Si}=\mathrm{O}$ double bond, the process responsible for the observed emission. This emission, however, is still nc size dependent, due to quantum confinement effects, thus explaining the observed blueshift. migration and trapping of excitons within nanostructures have been studied in both porous Si and Si nc formed by ion implantation (Pavesi, 1996; Linnros et al., 1999, as cited in Priolo et al., 2001). But Si nanocrystals emit light at room temperature in the range 700-1100 nm (Priolo et al., 2001, as cited in Priolo et al., 2001).

In order to realize the $\mathrm{Si}$ based light emitter in the technologically important $1.5 \mu \mathrm{m}$ range (Ennen et al., 1983, as cited in Suh et al., 2005), the Er-doping of Si has attracted great attention because of its promising future in the development of light-emitting diodes and lasers operating at a wavelength of $1.54 \mu \mathrm{m}$, which coincides with the absorption minimum of optical fibers (Park et al., 2005). The Er doping of Si nanocrystals (ncs) holds some promise for efficiently generating light emission, since Si nanocrystals in the presence of $\mathrm{Er}$ act as efficient sensitizers for Er ions (Polman, 1997; Seo \& Shin, 2001; Schmidt et al., 2002; Iacona et al., 2002, as cited in Park et al., 2005). 


\subsection{Optical activation of Er-doped silicon nanocrystals}

$\mathrm{Er}$ is an important rare earth material for optoelectronic devices due to its luminescence wavelength at about $1540 \mathrm{~nm}$, which coincides with a minimum loss in optical fibers. Erdoped nanocrystals of indirect-gap semiconductors like $\mathrm{Si}$ are being widely studied as they would open new possibilities for applications in optoelectronics and microelectronics, with the main advantage of being compatible with actual device technology. As shown (Coffa et al., 1994, as cited in Park et al., 2005) in the Auger excitation model, the electron-hole pairs are bound to Er-related states below the conduction band in Si ncs. The exactions can then recombine and thereby excite the Er ions with an excess energy to the difference between the bound state and the conduction band in Si ncs. When Er is introduced in the sample the Er-nc interaction is particularly strong. In this case the excited nc preferentially transfers its energy to the Er ion. The Er ion is excited in a high energy state and decays very rapidly in the first excited state $\left({ }^{4} I_{13 / 2}\right)$. At this stage its energy is too small to be transferred back to the $\mathrm{nc}$ and the Er remains excited until the radiative emission occurs at $1.54 \mu \mathrm{m}$ while the nc luminescence at around $800 \mathrm{~nm}$ is totally quenched (Kenyon et al., 1994; Fujii et al., 1997, 1998; Franzo`et al., 1999; Chryssou et al., 1999; Kenyon et al., 2000; Shin et al., 2000a; Franzo` et al., 2000; Kik et al., 2000, as cited in Priolo et al., 2001). Therefore in the presence of Er ions a transfer of the energy among Si nc is thought to be less probable (Priolo et al., 2001).

Excellent optical properties were obtained by using silicon-rich silicon oxide (SRSO), which consists of $\mathrm{Si}$ ncs embedded inside a $\mathrm{SiO}_{2}$ matrix (Kenyon et al., 1994; Fujii et al., 1997; Shin et al., 1998, as cited in Suh et al., 2005). By now, optical gain (Han et al., 2002, as cited in Suh et al., 2005) as well as efficient light-emitting diodes (Franzó et al., 2002, as cited in Suh et al., 2005) have been demonstrated using Er-doped SRSO. Theoretical calculation (Nishio et al., 2003) also showed that the radiative recombination rate for Amorphous Si quantum dots (aSi QDs) is higher by two or three orders of magnitude than that for Si ncs indicating that better performance can be obtained when a 1.54- $\mu \mathrm{m}$ light source fabricated using an Erdoped a-Si QD structure is employed. However, isolation of $\mathrm{Si}$ ncs inside the $\mathrm{SiO}_{2}$ matrix makes current injection into SRSO difficult. Thus, SRSO-based LEDs generally require either very high voltages (Franzó et al., 2002, as cited in Suh et al., 2005) or very thin SRSO layers that can limit the light output (Irrera et al., 2002, as cited in Suh et al., 2005). Furthermore, excitation occurs via impact excitation by energetic carriers, which raises questions about the long-term reliability of such devices.

\subsection{Optical activation of Er-doped silicon nanowires}

Compared with the isolation of Si nc, SiNWs have diameters in the range of 10-100 nm and with lengths exceeding $1 \mu \mathrm{m}$. Thus, Er-doped SiNWs may provide a very high areal density of $\mathrm{Er}^{3+}$ ions in the case of Er-doping. The ease of charge injection into, and transport along the SiNWs are expected to improve the photoluminescence (PL) intensity. Si/Er core-shell nanowires with erbium enriched at the surface (Wang \& Coffer, 2002) were fabricated successfully via a VLS process, which is modified by passing the He through a bubbler (heated to $\sim 144^{\circ} \mathrm{C}$ ) containing $\mathrm{Er}(\mathrm{tmhd})_{3}$ after $\mathrm{SiH}_{4}$ flow. This process results in introducing Er to the surface of SiNWs, as shown in Figure 2.1.

Detectable erbium emission at room temperature in a crystalline semiconductor is often difficult to achieve. But the anticipated $\mathrm{Er}^{3+}$ with $\mathrm{Er}^{3+}$ luminescence near $1.54 \mu \mathrm{m}$, associated with the $\left({ }^{4} \mathrm{I}_{13 / 2}\right) \rightarrow\left({ }^{4} \mathrm{I}_{15 / 2}\right)$ transition, is observed upon excitation at $488 \mathrm{~nm}$, as shown in Figure 2.2. However, it is regretted that the Photoluminescence (PL) intensity is very weak. 


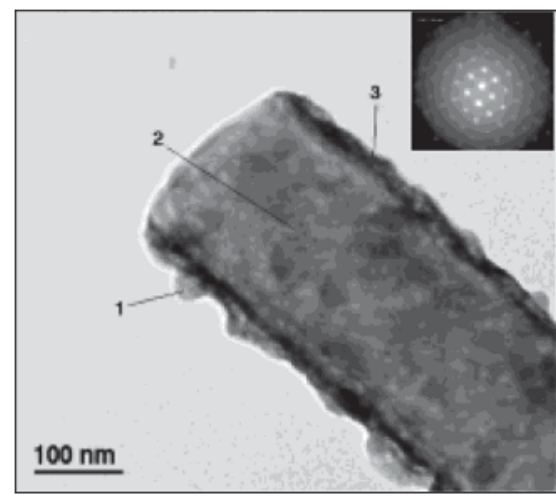

Fig. 2.1 A typical TEM image of a surface Er enriched Si wire (JEOL JEM-3010). Inset: SAED pattern from the center of the wire. EDX analysis for the marked three areas are presented: Si $96 \%$ (area 2), erbium concentration $\sim 12 \%$ (area 3), erbium $53 \%$ and silicon $47 \%$ (area 1).

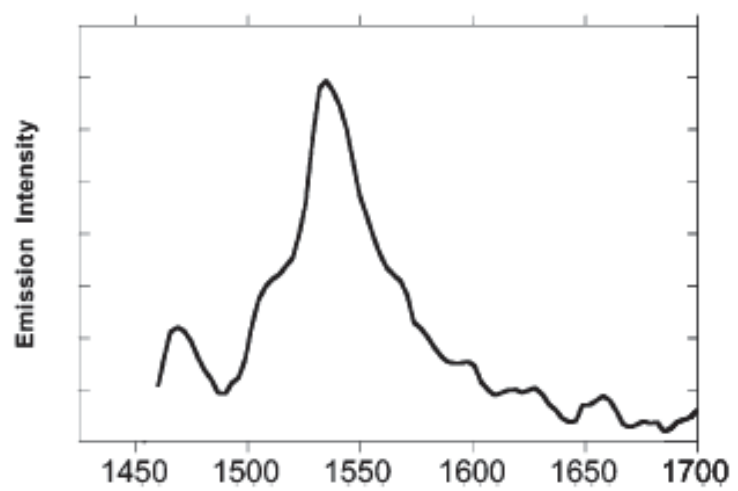

Fig. 2.2 Room-temperature photoluminescence (PL) spectrum of Er surface-enriched Si nanowires after a vacuum anneal, demonstrating the near-IR emission near $1540 \mathrm{~nm}\left(\lambda_{\mathrm{ex}}\right)$ $488 \mathrm{~nm})$.

\subsubsection{Improvement of PL intensity of Er-doped silicon nanowires}

\subsubsection{Silicon nanowires coating with $\mathrm{Er}$-doped $\mathrm{SiO}_{2}$ derived from sol-gel solutions}

As above mentioned, the optimum location for $\mathrm{Er}^{3+}$ is not inside $\mathrm{Si}$, but in the nanometerthin oxide shell right next to Si (Shin et al., 2000b; Kimura et al., 2003; Stepikhova et al., 1997, as cited in Suh et al., 2005). This suggests that rather than trying to dope Si-NWs directly, it would be preferable to coat the Si-NWs with high-quality Er-doped silica in order to optically activate the Si-NWs. Er coated SiNWs are achieved by using sol-gel derived Erdoped silica. The sol-gel technique is a low-temperature route widely employed to prepare thin film for integrated optic devices, because it can offer the homogeneous thin films at molecular scale and control of chemical purity. In this system, the pre-produced SiNWs are embedded inside an Er-doped silicon oxide film. 


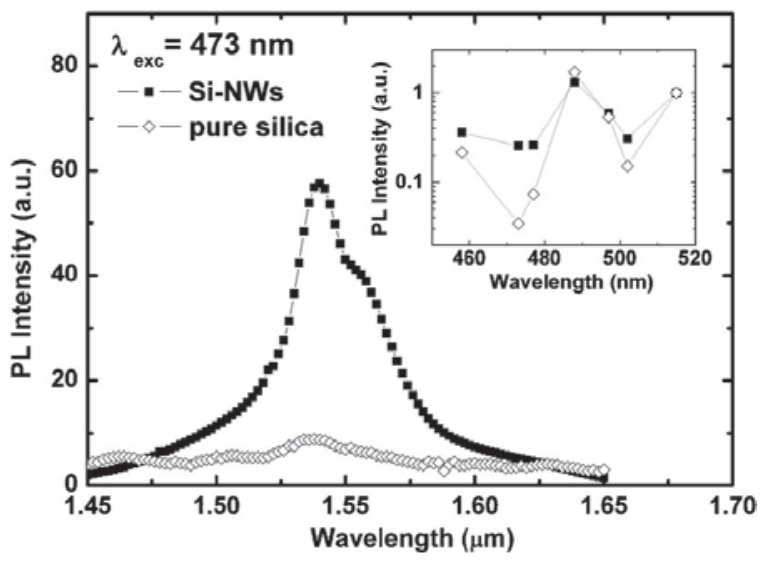

Fig. 2.3 Room temperature PL spectra of the Si-NWs and pure Er-doped silica film, pumped with the wavelength of $473 \mathrm{~nm}$. The inset shows the wavelength dependence of the PL peak intensities (Suh et al., 2005).

Figure 2.3 shows the room temperature PL spectra of the Si-NWs and the pure Er-doped silica thin film, pumped with the $473 \mathrm{~nm}$ line of an Ar laser. The $473 \mathrm{~nm}$ line was chosen because it is absorbed only by $\mathrm{Si}-\mathrm{NWs}$ and not directly by $\mathrm{Er}^{3+}$ ions. Hardly any luminescence from the pure silica film is not observed. However, the pure silica film does show $\mathrm{Er}^{3+}$ luminescence when $\mathrm{Er}^{3+}$ ions can directly absorb the pump photons, as shown in the inset. The strong $\mathrm{Er}^{3+}$ luminescence at $1.54 \mu \mathrm{m}$ from the Si-NWs indicates energy transfer from carriers in $\mathrm{Si}-\mathrm{NWs}$ to $\mathrm{Er}^{3+}$ ions.

Figure 2.4 shows the effect of temperature on the integrated $\mathrm{Er}^{3+} \mathrm{PL}$ intensities. The pure silica film was pumped using the $488 \mathrm{~nm}$ line of an Ar laser in order to directly excite the $\mathrm{Er}^{3+}$ ions. On the other hand, the Si-NWs were pumped using the $477 \mathrm{~nm}$ line of an Ar laser, which is not absorbed optically by $\mathrm{Er}^{3+}$ ions, in order to probe only those $\mathrm{Er}^{3+}$ ions that can be excited via carriers. The temperature dependence of $\mathrm{Er}^{3+}$ luminescence lifetimes are nearly identical, as is shown in the inset. The $\mathrm{Er}^{3+}$ luminescence lifetime from the pure silica film decreases from 13.6 to $11 \mathrm{~ms}$ as the temperature is raised from 25 to $300 \mathrm{~K}$, while that from the Si-NWs decreases from 8.3 to $6.9 \mathrm{~ms}$. Such complete suppression of thermal quenching of $\mathrm{Er}^{3+}$ luminescence cannot be due to any quantum effects of the large diameter of SiNWs (Suh et al., 2005). Given the identical temperature dependence of the $\mathrm{Er}^{3+}$ luminescence lifetime, the reduction of the $\mathrm{Er}^{3+}$ luminescence lifetime by $\mathrm{Si}-\mathrm{NWs}$ is attributed to the effect of increased effective refractive index (Snoeks et al., 1995) rather than any degradation of the quality of sol-gel derived silica film. Thus, it could be ensured that the $\mathrm{Er}^{3+}$ ions excited via carriers generated in Si-NWs are actually in the sol-gel derived Erdoped silica film that is coating the Si-NWs (Shin et al., 2000b; Kimura et al., 2003; Stepikhova et al., 1997), indicating that Si-NWs, even without quantum confinement effects, are much more effective for exciting $\mathrm{Er}^{3+}$ ions in an oxide layer on their surface. This conclusion is supported by the low-temperature PL spectra, as shown in Figure 2.5. The ${ }^{4} I_{13 / 2} \rightarrow{ }^{4} I_{15 / 2}$ transition responsible for the $1.54 \mu \mathrm{m} \mathrm{Er}{ }^{3+}$ luminescence is a parity-forbidden transition that occurs in part due to the effects of the crystal field, and the exact shape and position of the luminescence spectra depend on the chemical and structural environment of Er (Stepikhova et al., 1997). 


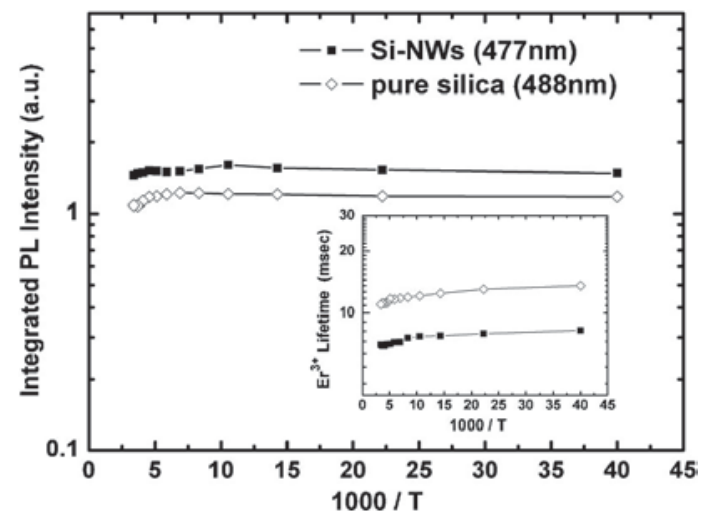

Fig. 2.4 The temperature dependence of $\mathrm{Er}^{3+}$ integrated PL intensities, showing the complete suppression of thermal quenching. The inset shows the temperature dependence of the luminescence lifetimes.

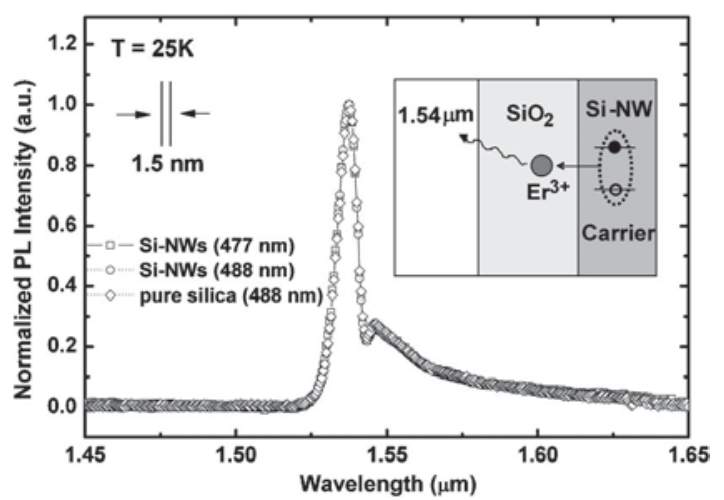

Fig. 2.5 Normalized PL spectra of pure Er-doped silica (488 nm), with Si-NWs (488 nm) and with Si-NWs $(477 \mathrm{~nm})$ at $25 \mathrm{~K}$. The spectra are completely idenctical within the spectral resolution, indicating that the luminescent $\mathrm{Er}^{3+}$ ions are all in silica. The inset shows the schematic description of the proposed $\mathrm{Er}^{3+}$ luminescence.

Therefore, the results indicate that by using sol-gel derived Er-doped silica to optically activate Si-NWs, we can simultaneously achieve the ease of carrier injection, high carriermediated $\mathrm{Er}^{3+}$ excitation efficiency, and high $\mathrm{Er}^{3+}$ luminescence efficiency in a thick, easily produced film with a very high areal density of $\mathrm{Er}^{3+}$ ions, thus providing a promising material platform for Si photonics. The effectiveness of Si-NWs in enhancing the $\mathrm{Er}^{3+}$ luminescence can be increased by simply increasing the density of Si-NWs. Furthermore, because the growth of Si-NWs and its coating by sol-gel derived Er-doped silica are performed separately, the two processes can be optimized separately.

\subsubsection{Silicon nanowires coating with Er-doped $\mathrm{SiO}_{2}$ and $\mathrm{Al}_{2} \mathrm{O}_{3}$ derived from sol-gel solutions}

$\mathrm{SiO}_{2}$ derived from sol-gel was used as a precursor to disperse $\mathrm{Er}^{3+}$ ions. But the film is uncontinuous and the erbium ions gather to clusters, which may induce the concentration 
quenching of the photoluminescence (PL) intensity. In fact, the concentration quenching at high concentration of Er should be avoided to realize the strong luminescence of the devices. $\mathrm{Al}_{2} \mathrm{O}_{3}$ is another promising material for high quality, low loss waveguide fabrication. Optical doping of thin $\mathrm{Al}_{2} \mathrm{O}_{3}$ films by Er ion implantation (van den Hoven et al., 1993, 1996) and by sol-gel technology (Feofilov, 1998; Patra, 2004) have been reported. Not only because the relatively high refraction index of $\mathrm{Al}_{2} \mathrm{O}_{3}\left(\mathrm{Al}_{2} \mathrm{O}_{3}, \mathrm{n}=1.64\right.$ is higher than $\left.\mathrm{SiO}_{2}(\mathrm{n}=1.45)\right)$ (Wang \& Lei, 2005) is expected to improve the optical transfer efficiency, but the similarity in valency and lattice constants between $\mathrm{Al}_{2} \mathrm{O}_{3}$ and $\mathrm{Er}_{2} \mathrm{O}_{3}$ may enable disperse high concentrations optical doping with Er (van den Hoven et al., 1993, 1996; Feofilov, 1998). Furthermore, Aluminium oxide possesses the low thermal expansion coefficient (Jaymes et al., 1996), high chemical durability, and good mechanical property, which are benefit to $\mathrm{Al}_{2} \mathrm{O}_{3}$ film derived from sol-gel solutions on $\mathrm{Si}$ wafer substrate. It is very important for the application of the optical devices (Jimenez de Castro et al., 2000; Wang et al., 2004a, 2004b; Armelao et al., 2005). In order to prevent the clustering of erbium ions in the silica network, $\mathrm{Al}$ ions could be added into the silicon oxide structure or completely aluminum oxide structure. Therefore, the optically harmful Er clustering could be prevented by the selective coordination of $\mathrm{Al}^{3+}$ around the $\mathrm{Er}^{3+}$ ions (Patra, 2004) allowing for a homogeneous dispersion of Er ions in the silicon oxide structure.
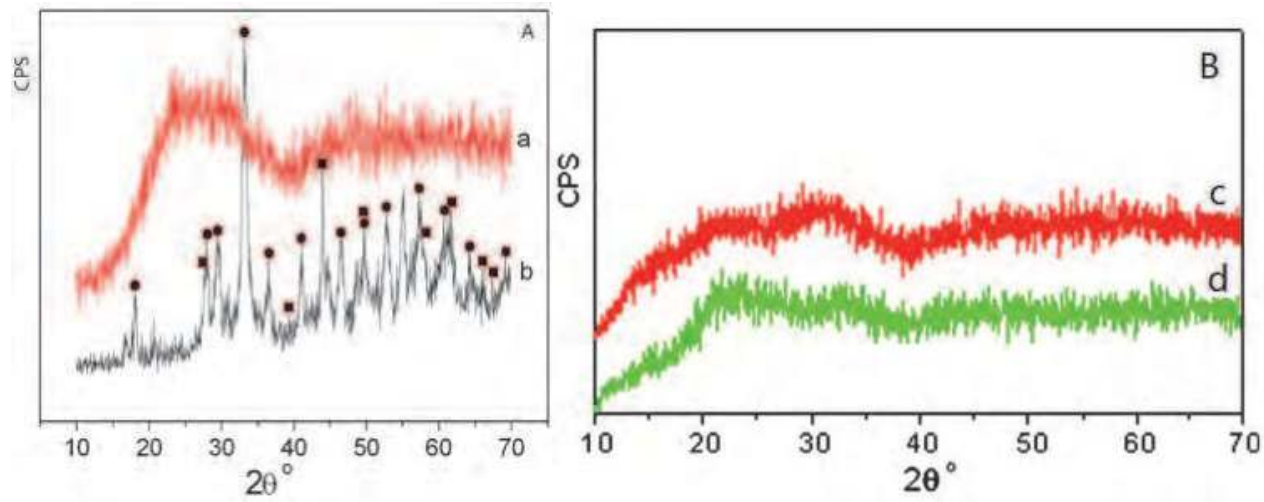

Fig. 2.6 X-ray diffraction patterns of (A-a (Ren, 2008) and B-c (Ren et al., 2007a)) Er-doped $\mathrm{SiO}_{2}$ derived from sol-gel heat-treated at $750^{\circ} \mathrm{C}(\mathrm{Er} / \mathrm{Si}=0.05),(\mathrm{A}-\mathrm{b}($ Ren, 2008)) Er-doped $\mathrm{Al}_{2} \mathrm{O}_{3}$ derived from sol-gel heat-treated at $750^{\circ} \mathrm{C}(\mathrm{Er} / \mathrm{Al}=0.10)$, and $(\mathrm{B}-\mathrm{d})$ (Ren et al., 2007a) Er-doped $\mathrm{Si}$ and $\mathrm{Al}$ oxides derived from sol-gel heat-treated at $750^{\circ} \mathrm{C}$. The hollow circle $(\mathbf{)})$ represents $\mathrm{Er}_{3} \mathrm{Al}_{5} \mathrm{O}_{12}$ peaks; the solid circle ( $\left.\mathbf{a}\right)$ represents $\mathrm{ErAlO}_{3}$ peaks.

In order to understand the relationship between the PL properties and the structures of Erdoped $\mathrm{Al}_{2} \mathrm{O}_{3}$, $\mathrm{Si}$ and $\mathrm{Al}$ oxides complex $(\mathrm{SiAlO})$ and $\mathrm{SiO}_{2}$ sol-gel films, the powder XRD patterns of heat-treated sol-gels at $750^{\circ} \mathrm{C}$ with compositions of Er-doped $\mathrm{SiO}_{2}$ (A-a and B-c), Er-doped SiAlO (B-d) and Er-doped $\mathrm{Al}_{2} \mathrm{O}_{3}(\mathrm{~A}-\mathrm{b})$ are tested, as shown in Figure 2.6 (Ren et al., 2007a, 2008). Figure 2.6 (A-a and B-c) shows the XRD pattern of Er-doped Si oxides. It shows the amorphous structure due to the short range ordering of Si network (Stepikhova et al., 2004). As shown in Figure 2.6 (B-d), the Er-doped Si-Al oxides also show an amorphous structure, indicating that the incorporation of $\mathrm{Al}$ into the $\mathrm{Si}$ network does not change the structures. However, it is expected that a more homogeneous incorporation of Er ions into 
Al-Si network compared to the Si network is likely by the selective coordination of $\mathrm{Al}^{3+}$ around the $\mathrm{Er}^{3+}$ ions. However, the $\mathrm{Er}_{3} \mathrm{Al}_{5} \mathrm{O}_{12}$ (PDFN 78-1451) phase and $\mathrm{ErAlO}_{3}$ (PDFN 240396) phase are observed as shown in Fig. 2.6(A-b), which is consistent with Tanner's report (Kenyon, 2002) where the mixture of $\mathrm{Er}_{3} \mathrm{Al}_{5} \mathrm{O}_{12}$ and $\mathrm{ErAlO}_{3}$ are achieved for concentrations at or below $10 \%$ Er doped into $\mathrm{Al}_{2} \mathrm{O}_{3}$ due to the valence match between the rare-earth ions $\left(\mathrm{Er}^{3+}\right)$ and the substituted cation $\left(\mathrm{Al}^{3+}\right)$. As a result, it allows the incorporation of $\mathrm{Er}^{3+}$ into the $\mathrm{Al}_{2} \mathrm{O}_{3}$ lattice (Hochbaum et al., 2005) despite of the large size difference between $\mathrm{Er}^{3+}$ $(0.89 \mathrm{~nm})$ and the $\mathrm{Al}^{3+}(0.53 \mathrm{~nm})$ (Tanner et al., 2004). It indicates that Er ions are homogeneous in $\mathrm{Al}_{2} \mathrm{O}_{3}$ even at high concentrations.

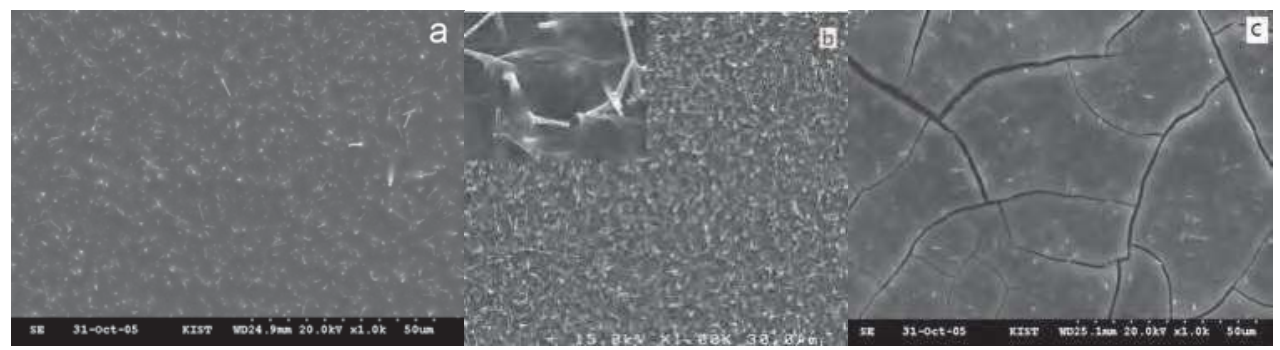

Fig. 2.7 SEM images of (a) SiNW-ErAlO (Ren, 2008), (b) SiNW-ErSiAlO (Si/Al=3/1) (Ren et al., 2007a) and (b) SiNW-ErSiO (Ren, 2008).

Figure 2.7 shows the SEM images of SiNW-ErAlO (a), SiNW-ErSiAlO (b) and SiNW-ErSiO (c) films. As shown in Figure 2.7, SiNW-ErAlO (a) and SiNW-ErSiAlO (b) film are continuous without cracks but numerous splits emerge in SiNW-ErSiO (c) film. A zoomed image further shows that the sol-gel solution has completely penetrated the SiNWs arrays, and had formed a crack-free, integrative film with tight SiNWs. The higher quality of film derived from Al-Si solution is due to the comparable thermal expansion coefficient of the film over that of the $\mathrm{Si}$ substrate. The thermal expansion coefficient of $\mathrm{SiO}_{2}, \mathrm{Al}_{2} \mathrm{O}_{3}$ and $\mathrm{Si}$ is $66 \times 10^{-6} / \mathrm{K}, 23 \times 10^{-6} / \mathrm{K}$ and $23 \times 10^{-6} / \mathrm{K}$, respectively. Thus, the cracks in the Er-Si oxide film are due to large differences in the thermal expansion coefficient between the $\mathrm{SiO}_{2}$ and the $\mathrm{Si}$ binary system. In addition, an addition of $\mathrm{Al}$ to the Si-oxide while maintaining its amorphous structures matches the thermal expansion coefficient of the film $\left(55 \times 10^{-6} / \mathrm{K}\right.$, according to the rule of mixture) to the $\mathrm{Si}$ substrate and suppressed the formation of cracks during the heat treatment. Thus, the reason of the high quality of SiNW-ErAlO and SiNW-ErSiAlO films are those the thermal expansion coefficient of the film over that of $S i$ substrate matched well whereas the cracks in SiNW-ErSiO film are due to large differences in thermal expansion coefficient between the $\mathrm{SiO}_{2}$ and the $\mathrm{Si}$ binary system.

In order to further understand the relationship between PL properties and the structures of Er-doped $\mathrm{Al}_{2} \mathrm{O}_{3}$ and $\mathrm{SiO}_{2}$ sol-gel films, the TEM of heat treated sol-gels at $750^{\circ} \mathrm{C}$ are tested. Figure 2.8 was TEM images of Er-doped $\mathrm{SiO}_{2}$ and Er-doped $\mathrm{Al}_{2} \mathrm{O}_{3}$. As shown in the inset of Figure 2.8a and Figure 2.8b, the Er-doped $\mathrm{SiO}_{2}$ is amorphous due to its out-of-order structure in long range but the Er-doped $\mathrm{Al}_{2} \mathrm{O}_{3}$ is crystal structure because the optically active $\mathrm{Er}^{3+}$ ion readily substitutes for aluminium ions occupying octahedral sites in alumina (Kenyon, 2002), which is consistent with the XRD results. As shown in Figure 2.8a and 2.8b, the cluster sizes of Er-doped $\mathrm{SiO}_{2}$ (about $300 \mathrm{~nm}$ ) are much larger than that of Er-doped $\mathrm{Al}_{2} \mathrm{O}_{3}(\leq 100 \mathrm{~nm})$, indicating that the dispersion of $\mathrm{Al}_{2} \mathrm{O}_{3}$ is better than that of $\mathrm{SiO}_{2}$. 

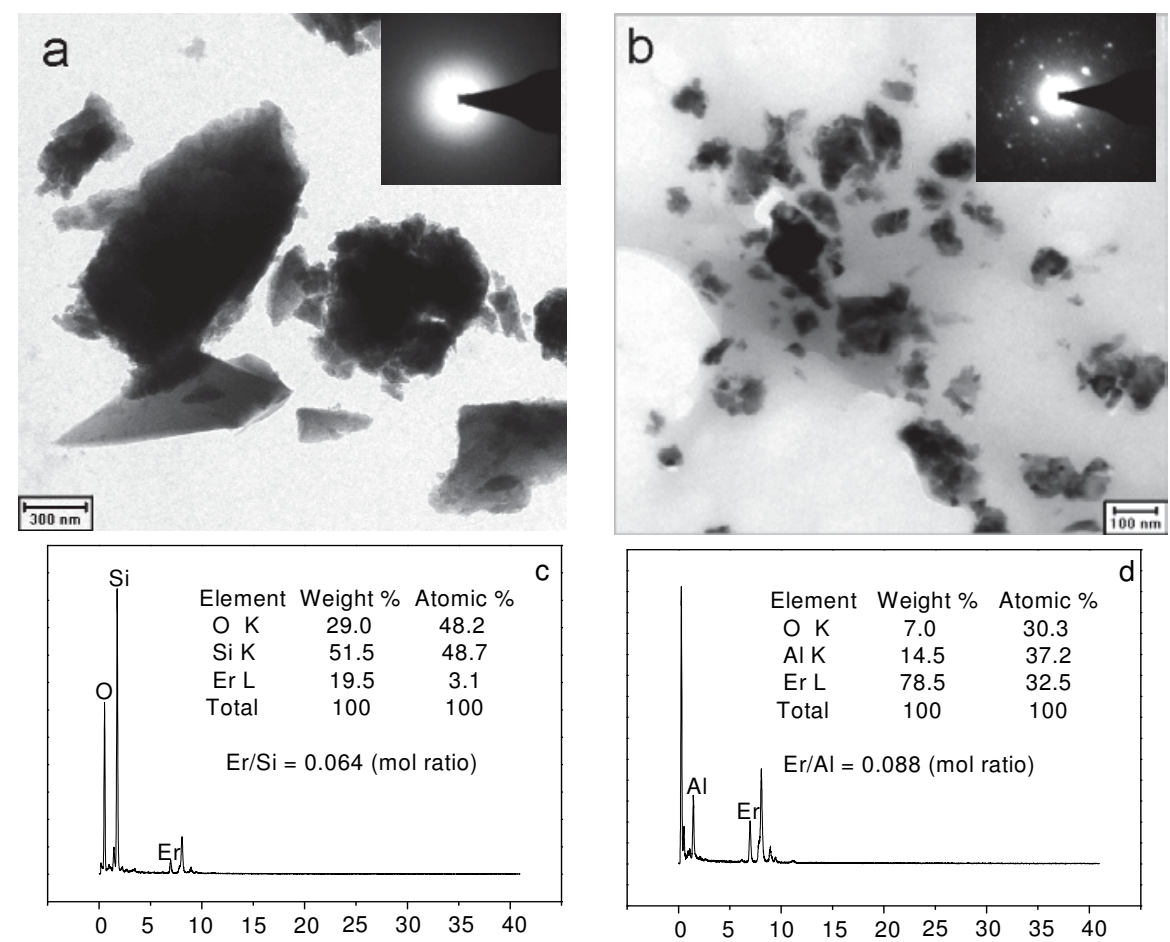

Fig. 2.8 TEM images and EDX of $(\mathrm{a}, \mathrm{c})$ Er-doped $\mathrm{SiO}_{2}$ derived from sol-gel heat-treated at $750^{\circ} \mathrm{C}$, inset is the selected area electron diffraction (SAED) pattern of the particles; (b, d) Erdoped $\mathrm{Al}_{2} \mathrm{O}_{3}$ derived from sol-gel heat-treated at $750^{\circ} \mathrm{C}$, inset is the SAED pattern of the particles (Ren, 2008).

Furthermore, the EDX results also show that Er ions are dispersed in the $\mathrm{SiO}_{2}$ and $\mathrm{Al}_{2} \mathrm{O}_{3}$, as shown in Figure 8c and 8d, the mol ratios of $\mathrm{Er} / \mathrm{Si}$ and $\mathrm{Er} / \mathrm{Al}$ are 0.064 and 0.088 respectively, which are close to the original mol ratios. As we have discussed that the crystal mixture of $\mathrm{Er}_{3} \mathrm{Al}_{5} \mathrm{O}_{12}$ and $\mathrm{ErAlO}_{3}$ created when Er ions are doped into $\mathrm{Al}_{2} \mathrm{O}_{3}$, but the Erdoped $\mathrm{SiO}_{2}$ is amorphous, and TEM images indicate that Er-doped $\mathrm{Al}_{2} \mathrm{O}_{3}$ clusters are much smaller than that of Er-doped $\mathrm{SiO}_{2}$ clusters. So it could be deduced that the dispersion of $\mathrm{Er}$ ions at high concentration in $\mathrm{Al}_{2} \mathrm{O}_{3}$ is better than that in $\mathrm{SiO}_{2}$.

Figure 2.9 shows the PL spectra of SiNW-ErSiO, SiNW-ErSiAlO and SiNW-ErAlO at the room temperature, pumped with the $477 \mathrm{~nm}$ line of an Ar laser. The $477 \mathrm{~nm}$ line was chosen because it is absorbed only by SiNWs and not directly by $\mathrm{Er}^{3+}$ ions (Suh et al., 2005), which is also confirmed by our result, as shown in Figure 2.9A-a. No peak is observed in Figure 2.9Aa when only Er-doped $\mathrm{SiO}_{2}$, Er-doped $\mathrm{SiAlO}$ or Er-doped $\mathrm{Al}_{2} \mathrm{O}_{3}$ without $\mathrm{SiNWs}$ is pumped with the $477 \mathrm{~nm}$ line. This ensures that $\mathrm{Er}^{3+}$ excitation occurs via carriers only, and represents an accurate simulation of the situation under current injection. However we observed strong $\mathrm{Er}^{3+}$ luminescence at $1534 \mathrm{~nm}$ (the PL intensity is 66.3 a.u.) from the SiNW$\mathrm{ErSiO}$ even with the high Er concentration $(\mathrm{Er} / \mathrm{Si}=0.05$, concentration 9 at.\%), indicating that SiNWs provide a very high areal density of Er and energy transfer from carriers in 
SiNWs to $\mathrm{Er}^{3+}$ ions dispersed in $\mathrm{SiO}_{2}$, as shown in Figure 2.9A-b. It can be seen that the Full Width at Half Maximum (FWHM) of the luminescence is about $40.5 \mathrm{~nm}$. This emission band is very typical and is attributed to the Stark splitting of $\mathrm{Er}^{3+}$ embedded in an amorphous structure plus small additional inhomogeneous and homogeneous broadening (Polman et al., 1991). Similarly, a strong Er luminescence was observed $1.534 \mu \mathrm{m}$ from the SiNWs coated with Er-doped Si-Al oxide, as shown in Figure 2.9B-d, indicating an energy transfer from carriers in the SiNWs to the $\mathrm{Er}^{3+}$ ions. In addition, it can be seen that the FWHM (full width at half maximum) of the luminescence is approximately $56 \mathrm{~nm}$. This emission band structure is especially typical, and may be attributed to the Stark splitting of $\mathrm{Er}^{3+}$ embedded in the amorphous structure. It could also be attributed to the presence of many different environments for $\mathrm{Er}^{3+}$ ions in the binary $\mathrm{Si}-\mathrm{Al}$ oxides. The broadening of the spectra suggests a wider and homogeneous distribution of $\mathrm{Er}^{3+}$ sites in the matrix. As a result, the PL intensities of SiNW-ErSiO and SiNW-ErSiAlO are similar except that the film quality of SiNW-ErSiAlO id better than that of SiNW-ErSiO after addition of aluminum sol-gel into that of Silicon sol-gel.
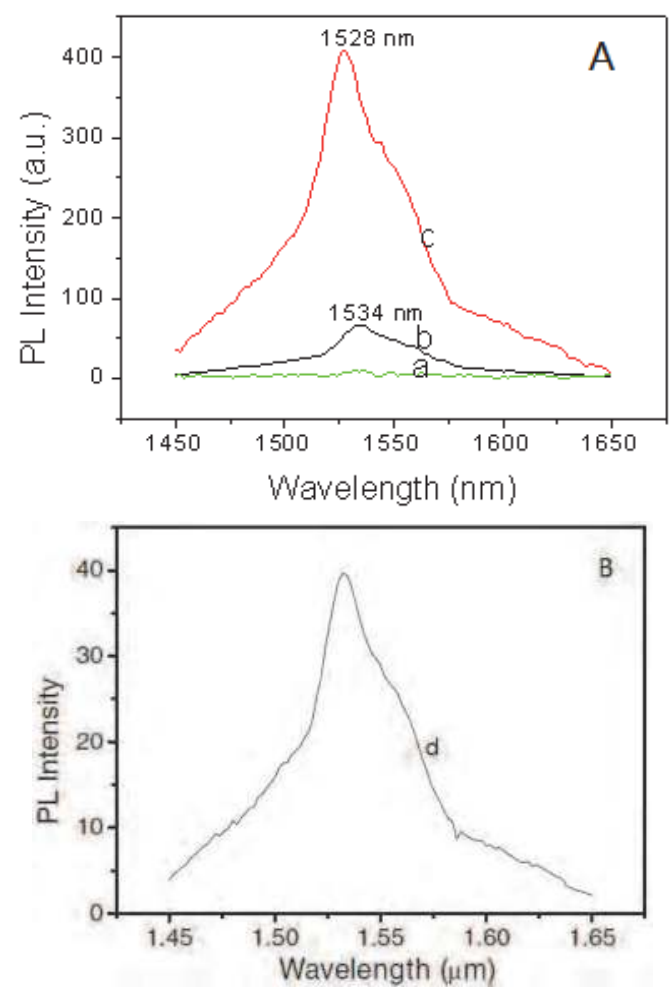

Fig. 2.9 Room temperature PL spectra of (A-a) (Ren, 2008) Er-doped $\mathrm{SiO}_{2}(\mathrm{Er} / \mathrm{Si}=0.05)$, Erdoped $\mathrm{Si}-\mathrm{Al}$ oxides $(\mathrm{Er} /(\mathrm{Si}+\mathrm{Al})=0.05, \mathrm{Si} / \mathrm{Al}=3: 1)$ and Er-doped $\mathrm{Al}_{2} \mathrm{O}_{3}(\mathrm{Er} / \mathrm{Al}=0.10)$ without SiNWs, (A-b) (Ren, 2008) SiNW-ErSiO (Er/Si = 0.05), (A-c) (Ren, 2008) SiNW-ErAlO $(\mathrm{Er} / \mathrm{Al}=0.10)$ and $(\mathrm{B}-\mathrm{d})($ Ren et al., 2007a) SiNW-ErSiAlO $(\mathrm{Er} /(\mathrm{Si}+\mathrm{Al})=0.05, \mathrm{Si} / \mathrm{Al}=3: 1)$ films heat-treated at $750^{\circ} \mathrm{C}$, wave guide with $477 \mathrm{~nm}$ excitation from $\mathrm{Ar}+$ laser. 
However, the PL spectrum of SiNW-ErAlO is shown in Figure 2.9A-c. Stronger $\mathrm{Er}^{3+}$ luminescence (the PL intensity is about 407.6 a.u.) at $1528 \mathrm{~nm}$ from the SiNW-ErAlO is observed, which is approximate six times higher than that of SiNW-ErSiO, indicating the concentration quenching is not obvious even at so high Er concentration (Er/ $\mathrm{Al}=0.1$ ), and there is more energy transfer from carriers in SiNWs to $\mathrm{Er}^{3+}$ ions in $\mathrm{Al}_{2} \mathrm{O}_{3}$ medium. Perhaps the reasons include two aspects. One is that $\mathrm{Er}$ ions with high concentration in $\mathrm{Al}_{2} \mathrm{O}_{3}$ disperse better than $\mathrm{Er}$ ions in $\mathrm{SiO}_{2}$, which excludes the concentration quenching. The other is that $\mathrm{Al}_{2} \mathrm{O}_{3}$ has an even higher refraction index, so it couples more efficiently to semiconductor laser materials. And waveguides with smaller dimensions and tighter optical modes can be produced. Moreover, an obvious blue shift of luminescence peak occurs in Figure 2.9A-c and the FWHM is about $46.9 \mathrm{~nm}$, which is wider than that of SiNWs coating with Er-doped $\mathrm{SiO}_{2}$. It is known that the main reason for the broadening is the local crystal field symmetry at the rare earth ion site and the luminescence spectra of Er-doped nanoparticles are depended on the host structure (Patra, 2004). The XRD results and SAED patterns have shown that the crystal mixture of $\mathrm{Er}_{3} \mathrm{Al}_{5} \mathrm{O}_{12}$ and $\mathrm{ErAlO}_{3}$ created when Er ions are doped into $\mathrm{Al}_{2} \mathrm{O}_{3}$, but the Er-doped $\mathrm{SiO}_{2}$ is amorphous, which change the local structure around $\mathrm{Er}^{3+}$ ions (d'Acapito et al., 2001). Perhaps these are the reasons of the blue shift of luminescence peak and broadening of FWHM.

\subsubsection{Controlled PL of Er-doped silicon nanowires}

As mentioned, there is a fixed method for preparing Er-doped SiNWs as following processes. Firstly, sputtered $\mathrm{Au}$ nanoparticles were employed as the catalyst and the NWs' growth proceeded through a vapor-liquid-solid (VLS) crystal growth mechanism. Then, the long SiNWs were dipped into Sol-gel solutions by surface coating with Er-doped silica or other materials. That is because the optimum locations for $\mathrm{Er}$ ions are not inside $\mathrm{Si}$, but in the nanometer thin oxide shell right next to Si (Kimura et al., 2003; Shin et al., 2000b; Stepikhova et al., 1997). As a result, rather than trying to dope SiNWs directly, it would be preferable to coat the SiNWs with high quality, Er-doped oxides by sol-gel in order to optically activate the SiNWs. Lastly, the Er-doped SiNWs derived from sol-gel solution are sintered.

Controlled growth of well-ordered Er-doped SiNWs is crucial, and would eliminate much of the processing associated with device fabrication. Selective growth of SiNWs via a VLS mechanism were achieved using an ion implantation mask, (Sood et al., 2006) lithographically defined regions of SiNW growth by thin film evaporation (Gangloff et al., 2004; Islam et al., 2004) and seeding colloids (Hochbaum et al., 2005). These methods employ expensive or complex processing techniques, but are unfit for the controlled growth of SiNWs and selective coating of Er-doped solutions at the same time.

However, combined sol-gel techniques and gold colloids, a simple technique to achieve patterned growth of SiNWs coating with Er-doped aluminous film is presented. The advantage of this method is that the growth of patterned SiNWs, the doping of Er ions and the sintered process are completed by one step. The Er-doped aluminium gels are calcined to be powders when SiNWs are grown by a VLS mechanism, removing sintered process, so the energy consume is reduced considerable (Ren et al., 2007). SiNWs grew from a solutionbased precursor containing ASB $\left(\mathrm{Al}\left(\mathrm{O}-\mathrm{sec}-\mathrm{C}_{4} \mathrm{H}_{9}\right)_{3}\right)$, hydrogen tetrachloroaurate $\left(\mathrm{HAuCl}_{4}\right)$ and Erbium by VLS mechanism for optical activation. In this process, the functional materials, Au nanoparticles and Er ions, are all evenly dispersed in the sol-gel solution at the same time. Furthermore, ASB was selected as the precursor to disperse Er ions because of its relatively high refraction index $(n=1.64)$ waveguides compared with $\mathrm{SiO}_{2}(n=1.45)$, leading 
to efficient pumping and amplification (Wang \& Lei, 2005), lower thermal expansion coefficient (Jaymes et al., 1996). And aluminum could also be either a network former, supplying non-bridging oxygen bonds, or an octahedral-coordinated network modifier (Ryu \& Kim, 1995). Moreover, the solution-based precursor allows locating gold/Aluminium gel on any well-defined position on substrate by shadow mask, printing, or soft lithography methods, which could facilitate the integration of SiNWs for characterization and devices. Micropatterns of GeNWs have been grown in a high yield on sol-gel prepared gold/silica substrate by using shadow mask with the help of an additive agent to keep a continuous film (Pan et al., 2005).
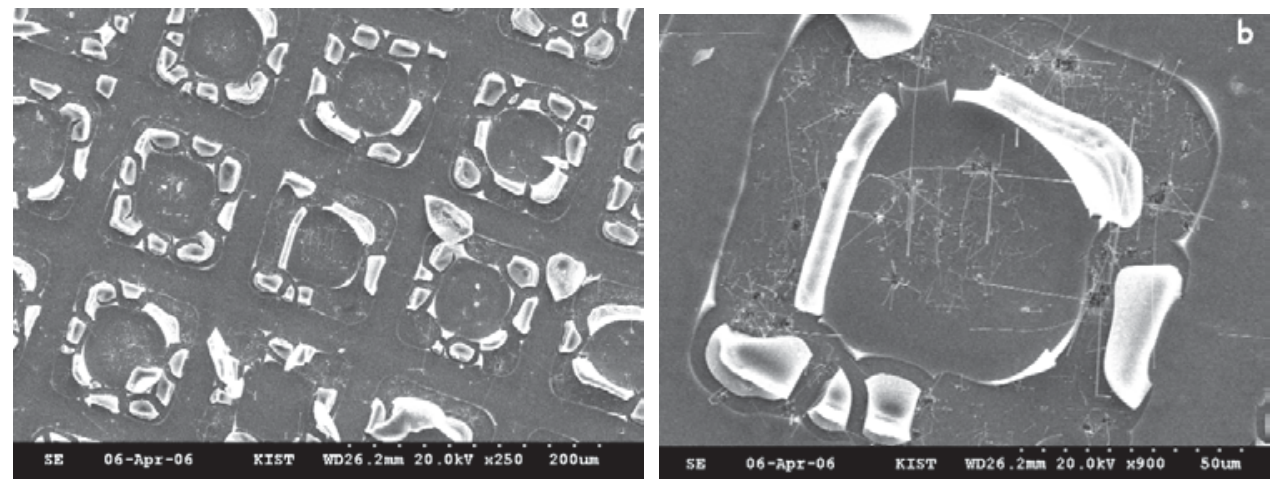

Fig. 2.10 SEM images of Si nanowires patterns grown from sol-gel prepared gold/Er-doped aluminous film by using TEM grids as the masks (a) the ordered arrays of Si nanowires (b) High-magnification image showing no unwanted nanowires grown in the interspaces (Ren et al., 2007b).

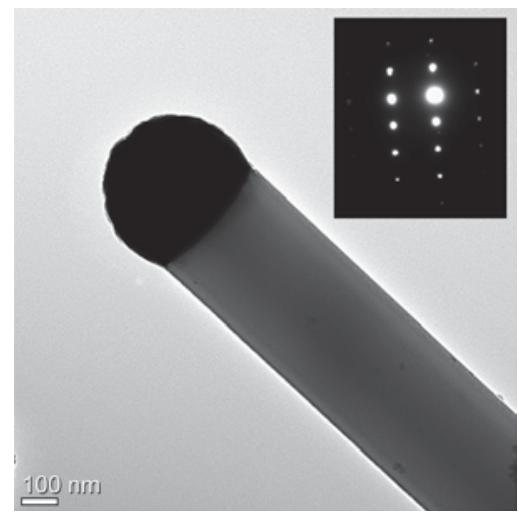

Fig. 2.11 High-magnification TEM image of an individual Si nanowire grown from sol-gel prepared gold/Er-doped aluminous film with a hemispherical Au nanoparticle located at the tip (Ren et al., 2007b).

Figure 2.10 is a SEM image of SiNW pattern produced by using a G200 copper TEM grid as the mask. As shown in Figure 2.10(a), the ordered arrays are obtained. And there is no 
unwanted nanowires grown in the interspaces except the obtained nanowires in the square area as shown in Figure 2.10(b), indicating that the spatial resolution of the patterns can be well controlled by the resolution of the mask used. Moreover, the SiNWs are tipped with an $\mathrm{Au}$ nanoparticle (determined by energy-dispersive X-ray (EDX) spectroscopy) with diameter comparable to the connected nanowire (Figure 2.11), thus showing a typical VLS growth feature. This result suggests that the growth of SiNWs occurs through an $\mathrm{Au}$ particle-catalyzed VLS growth mechanism even the gold nanoparticles dispersed in sol-gel solution. In addition, the dense of nanowires could be controlled by the amount of gold nanoparticles, and the thickness of the gel film could also be adjusted through changing the ASB concentration. Moreover, other techniques such as soft lithography (Kind et al., 2000; Huang et al., 2000) and direct printing (Cassell et al., 2001) could also be used to print the gold-containing solution to a desired position on the substrate surface, which might facilitate the integration of Si nanowires into devices.

Figure 2.12 is the XRD pattern of the Er -doped aluminous sol-gel materials sintered at $900^{\circ} \mathrm{C}$. The characteristic XRD pattern of $\mathrm{Er}_{3} \mathrm{Al}_{5} \mathrm{O}_{12}$ phase (PDF 78 1451) is observed, indicating that the $\mathrm{Al}^{3+}$ cations are substituted by the $\mathrm{Er}^{3+}$ rare-earth ions sintered at $900^{\circ} \mathrm{C}$ due to the valence match between the $\mathrm{Er}^{3+}$ ions and the substituted $\mathrm{Al}^{3+}$ ions, which is consistent with Tanner's report (Tanner et al., 2004) where the mixture of $\mathrm{Er}_{3} \mathrm{Al}_{5} \mathrm{O}_{12}$ and $\mathrm{ErAlO}_{3}$ are achieved for concentrations at or below $10 \%$ Er doped into $\mathrm{Al}_{2} \mathrm{O}_{3}$ due to the valence match between the rare-earth ions $\left(\mathrm{Er}^{3+}\right)$ and the substituted cation $\left(\mathrm{Al}^{3+}\right)$. As a result, it allows the incorporation of $\mathrm{Er}^{3+}$ into the $\mathrm{Al}_{2} \mathrm{O}_{3}$ lattice (Hochbaum et al., 2005) despite of the large size difference between $\mathrm{Er}^{3+}(0.89 \mathrm{~nm})$ and the $\mathrm{Al}^{3+}(0.53 \mathrm{~nm})$ (Tanner et al., 2004)l. Moreover, the $\theta-\mathrm{Al}_{2} \mathrm{O}_{3}$ phase (PDF 35 0121) were observed, which is consistent with former reports (Wang et al., 2004a, 2004b) that when the sintered temperature is at $900^{\circ} \mathrm{C}$, the $\gamma-\mathrm{Al}_{2} \mathrm{O}_{3}$ transfer to $\theta-\mathrm{Al}_{2} \mathrm{O}_{3}$ phase. In addition, the small peaks of the $\mathrm{Er}_{2} \mathrm{O}_{3}$ (PDF 77 0464) phase are also observed.

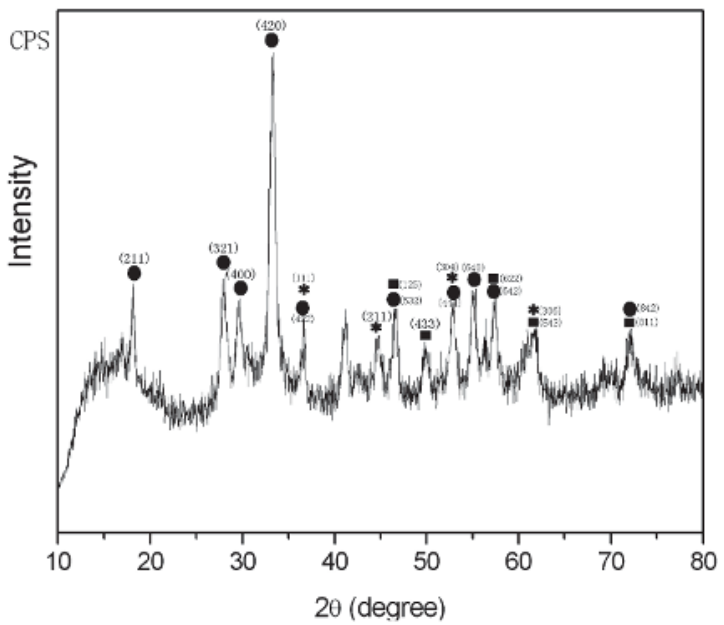

Fig. 2.12 X-ray diffraction patterns of Er-doped aluminous film sintered at $900{ }^{\circ} \mathrm{C}$. The solid circle $(\bullet)$ represents $\mathrm{Er}_{3} \mathrm{Al}_{5} \mathrm{O}_{12}$ peaks; the solid square $(\bullet)$ represents $\mathrm{Er}_{2} \mathrm{O}_{3}$ peaks; the star $\left(^{*}\right)$ represents $\theta-\mathrm{Al}_{2} \mathrm{O}_{3}$ peaks (Ren et al., 2007b). 


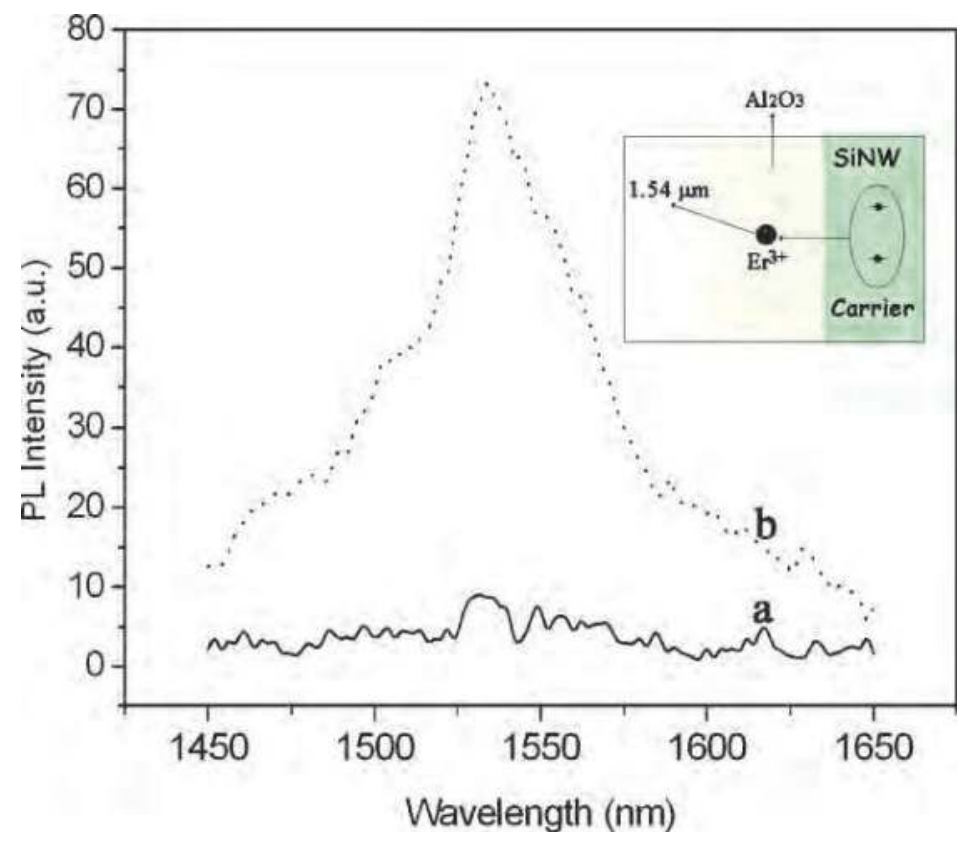

Fig. 2.13 Room temperature PL spectra of SiNWs grown from sol-gel prepared gold/Erdoped aluminous film at $900{ }^{\circ} \mathrm{C}$, wave guide with $477 \mathrm{~nm}$ excitation from $\mathrm{Ar}^{+}$laser. (a) no SiNWs (b) with SiNWs. The inset shows the schematic process of carrier transfer from SiNW to Er ion (Ren et al., 2007b).

Figure 2.13 shows the room temperature PL spectra of Si nanowires patterned grown on solgel prepared gold/Er-doped aluminous film, pumped with the $477 \mathrm{~nm}$ line of an Ar laser at room temperature. The $477 \mathrm{~nm}$ line was chosen because it is absorbed only by NWs and not directly by Er ions (Suh et al., 2005). This ensures that $\mathrm{Er}^{3+}$ excitation occurs via carriers only, and represents an accurate simulation of the situation under current injection, which has been confirmed by our result, as shown in Figure 2.13a. No peak is observed in Figure 13a when only Er-doped $\mathrm{Al}_{2} \mathrm{O}_{3}$ without $\mathrm{SiNWs}$ is pumped with the $477 \mathrm{~nm}$ line. This ensures that $\mathrm{Er}^{3+}$ excitation occurs via carriers only, and represents an accurate simulation of the situation under current injection. Nevertheless, we observed strong $\mathrm{Er}^{3+}$ luminescence at $1534 \mathrm{~nm}$ (the PL intensity is 75 a.u.) from the SiNWs coating with Er-doped $\mathrm{Al}_{2} \mathrm{O}_{3}$ as shown in Figure 2.13b, indicating that energy transfer from carriers in SiNWs to $\mathrm{Er}^{3+}$ ions dispersed in $\mathrm{Al}_{2} \mathrm{O}_{3}$. The schematic process is shown in the inset, which suggests that SiNWs are more effective for exciting Er ions in an oxide layer on their surface.

However, when the Si nanowires patterned grown on sol-gel prepared gold/Er-doped aluminous film are excited by the $488 \mathrm{~nm}$ line of an Ar laser at room temperature, reflecting the ${ }^{4} I_{15 / 2} \rightarrow{ }^{4} F_{7 / 2}$ and ${ }^{4} I_{15 / 2} \rightarrow{ }^{4} H_{11 / 2}$, the PL intensity (about 550 a.u.) is improved largely as shown in Figure 2.14. It could be explained that the $488 \mathrm{~nm}$ line of an Ar laser could excite not only $\mathrm{Si}$ nanowires, but also the $\mathrm{Er}^{3+}$ ions directly. The schematic process is shown in the inset. As a result, the excited Er concentrations are increased, indicating that the optically excited and carrier-excited Er ions are all possible. 


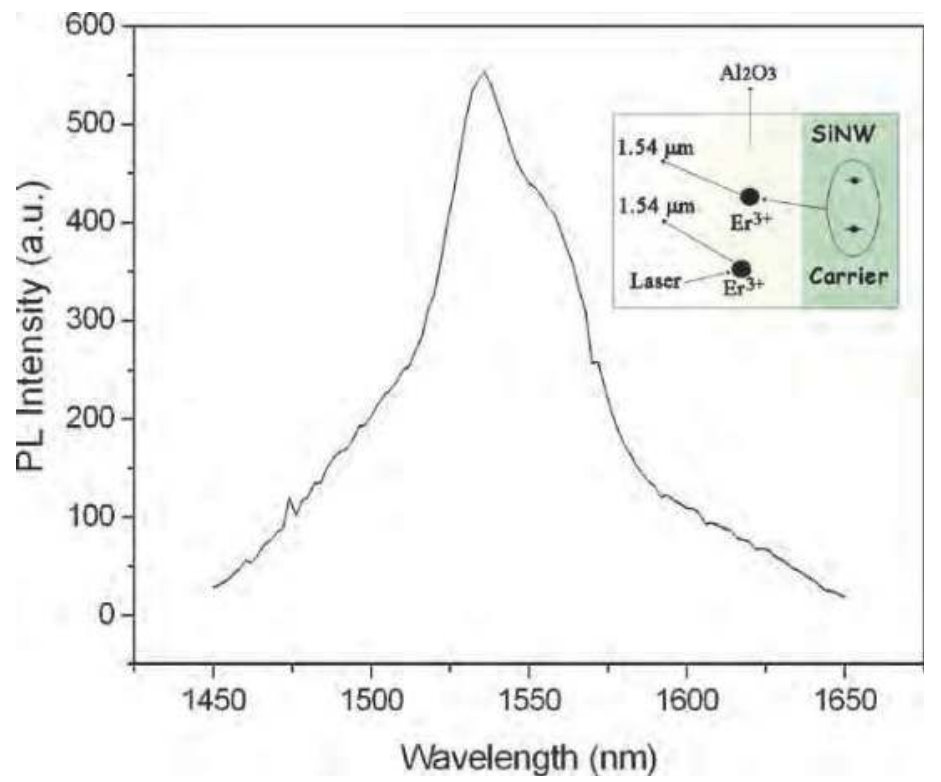

Fig. 2.14 Room temperature PL spectra of SiNWs grown from sol-gel prepared gold/Erdoped aluminous film at $900{ }^{\circ} \mathrm{C}$, wave guide with $488 \mathrm{~nm}$ excitation from $\mathrm{Ar}^{+}$laser. The inset shows the schematic process of carrier transfer from SiNW to Er ion and excited Er ion directly (Ren et al., 2007b).

\section{Other nanowires for PL, such as Ge nanowires}

Ge nanowires (GeNWs) is another promising nanowires due to its high carrier mobility and a small band gap (Gu et al., 2001; Wang \& Dai, 2002). Germanium is also an important semiconducting electronic material with indirect band gap. Moreover, the direct-gap (0.88 $\mathrm{eV})$ is close to its indirect gap $(0.75 \mathrm{eV})$ in $\mathrm{Ge}$, predicting that quantum confinement effects would appear more pronounced in Ge than Si. The optical activation of GeNWs doping with Er ions (Er-GeNWs) instead of SiNWs will also be achieved and the PL intensity at $1540 \mathrm{~nm}$ should be improved largely. But a major limitation is cooperative interactions, such as up conversion and fast energy migration between $\mathrm{Er}^{3+}$ ions, limiting emission efficiency at high Er concentration (Snoeks et.al.,1997). Ytterbium is widely used to improve the PL intensity of Er ions because $\mathrm{Yb}$ is a well-known sensitizer for the Er emission at $1540 \mathrm{~nm}$ due to fast energy transfer from the $\mathrm{Yb}$ ions to Er centers and no up conversion in $\mathrm{Yb}-\mathrm{Yb}$, and absorption band of $\mathrm{Yb}$ ions cover a broad extent from $850 \mathrm{~nm}$ to $1000 \mathrm{~nm}$ (Kozanecki et al., 1999, 2001).

Thus coating the SiNWs/GeNWs with high quality, Er/Er:Yb doped oxides by sol-gel are produced in order to optically activate the SiNWs/GeNWs (Ren et al., 2007c). Figure 3.1 shows the scanning electron microscope (SEM) image of as-grown SiNWs (a), GeNWs (b) for further coating sol-gel solutions as substrate and Er:Yb-SiNWs (c) and Er:Yb-GeNWs (d). As shown in Figure 3.1(a), the dense arrays of straight SiNWs by VLS are well aligned. The SiNWs lie at an angle of about $60^{\circ}$ from the surface normal, which are about $100 \mathrm{~nm}$ in diameter and $10 \mu \mathrm{m}$ in length. Similarly, we also obtained GeNWs with smaller than $100 \mathrm{~nm}$ 
in diameter and $10 \mu \mathrm{m}$ in length in Figure 3.1(b). As shown in Figure 3.1(c) and 3.1(d), both films are continuous without any cracks. The sol-gel solution has completely penetrated into the SiNWs and GeNWs arrays, forming a crack-free, integrative film tight of NWs, even after sintered at $750^{\circ} \mathrm{C}$, the film still keeps continuous and the NWs can also be seen well, indicating that $\mathrm{Er}$ and $\mathrm{Yb}$ ions dispersed in the oxide film derived from sol-gel solutions are continuous to coat the SiNWs/GeNWs with high quality. These are important for the applications of planar devices.
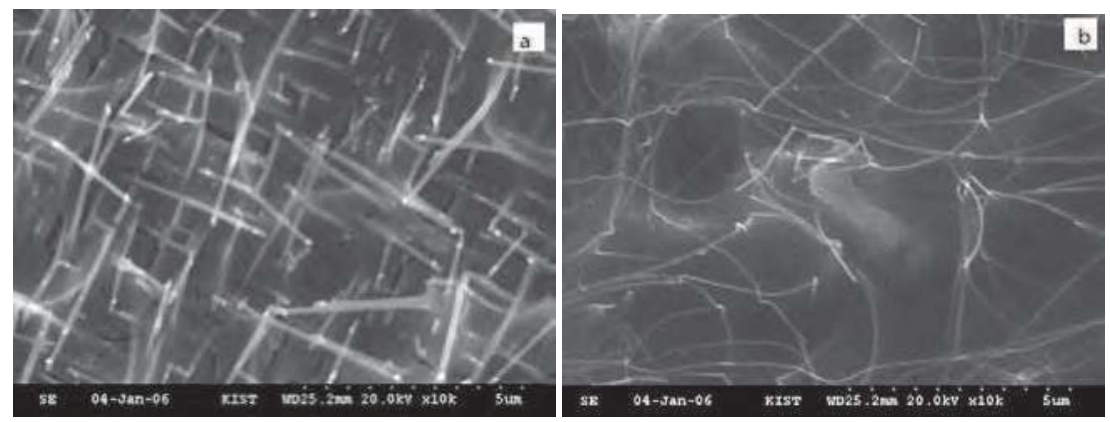

Fig. 3.1 SEM image of (a) Er:Yb-SiNWs, (b) Er:Yb-GeNWs. Er:Yb codoped Si-Al oxides coating on NWs films heated at $750^{\circ} \mathrm{Cderived}$ from the sol-gel solution ( $\mathrm{Si} / \mathrm{Al}=3: 1$ ) (Ren et al., 2007c).

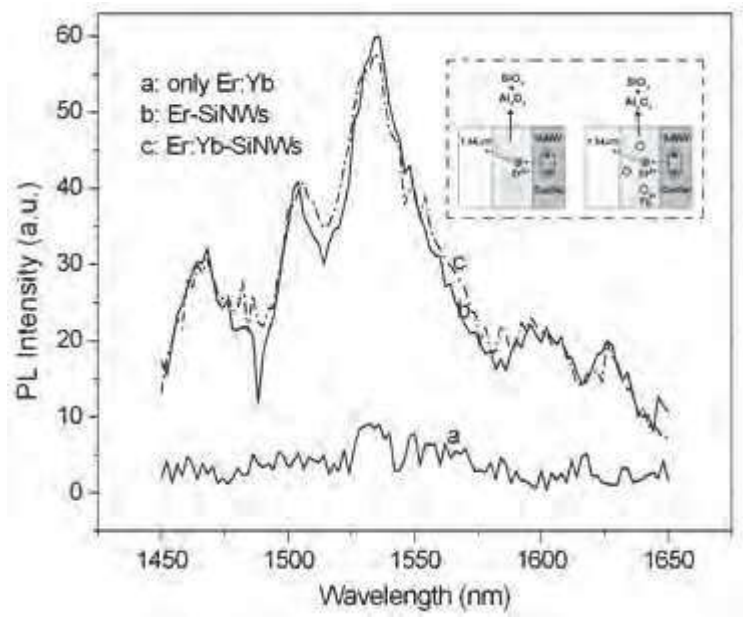

Fig. 3.2 Room temperature PL spectra of Er:Yb codoped Si-Al oxides coating SiNWs film heat-treated at $750^{\circ} \mathrm{C}$, wave guide with $477 \mathrm{~nm}$ excitation from an $\mathrm{Ar}^{+}$laser. ( $\mathrm{Si} / \mathrm{Al}=3: 1$ ) (a) Er:Yb codoped Si-Al oxides without SiNWs, (b) Er-SiNWs, (c) Er:Yb-SiNWs, the inset is the corresponding schematic route of optical activation of SiNWs (Ren et al., 2007c).

Figure 3.2 shows the room temperature PL spectra of Er-SiNWs and Er:Yb-SiNWs sintered at $750^{\circ} \mathrm{C}$, pumped with the $477 \mathrm{~nm}$ line of an Ar laser. The $477 \mathrm{~nm}$ line was chosen because it is absorbed only by NWs and not directly by Er and Yb ions (Suh et al., 2005). This ensures 
that $\mathrm{Er}^{3+}$ excitation occurs via carriers only, and represents an accurate simulation of the situation under current injection. As shown in Figure 3.2(a), hardly any luminescence from the Er or Er: $\mathrm{Yb}$ codoped $\mathrm{SiO}_{2}-\mathrm{Al}_{2} \mathrm{O}_{3}$ without $\mathrm{SiNWs}$ is observed, which is consistent with the previous report (Suh et al., 2005) that either $\mathrm{Yb}$ or Er ions are not excited by this $477 \mathrm{~nm}$ wavelength laser, or there is no energy transfer to $\mathrm{Er}$ ions. However, a strong $\mathrm{Er}^{3+}$ luminescence (PL intensity is about 60 a.u.) at $1534 \mathrm{~nm}$ from Er-SiNWs was observed as shown in Figure 3.2(b), indicating SiNWs are excited by $477 \mathrm{~nm}$ wavelength and energy transfer from carriers in SiNWs to $\mathrm{Er}^{3+}$ ions. Unimaginably, the PL intensity (57.8 a.u. at $1534 \mathrm{~nm}$ ) of Er:YbSiNWs was affected weakly after codoping $\mathrm{Yb}$ with $\mathrm{Er}, 15$ as shown in Figure 2.16(c), indicating that energy transfer from carriers in SiNWs not to $\mathrm{Yb}$ ions but to Er ions only. This result further confirms that the pumped energy of $477 \mathrm{~nm}$ wavelengths is directly absorbed by SiNWs, not by Er or $\mathrm{Yb}$ ions, suggesting that the $\mathrm{Yb}$ ions are not sensitizer for the Er emission at $1534 \mathrm{~nm}$ after SiNWs take part in the optical excitation and energy transfer.

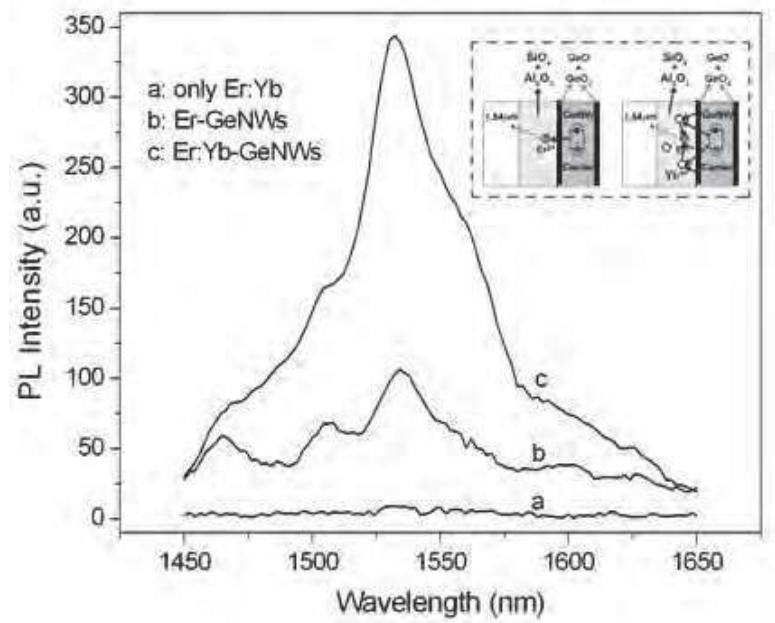

Fig. 3.3 Room temperature PL spectra of Er:Yb codoped Si-Al oxides coating GeNWs film heat-treated at $750^{\circ} \mathrm{C}$, wave guide with $477 \mathrm{~nm}$ excitation from an $\mathrm{Ar}^{+}$laser. (Si/ $\mathrm{Al}=3: 1$ ) (a) Er:Yb codoped Si-Al oxides without GeNWs, (b) Er-GeNWs, (c) Er:Yb-GeNWs, the inset is the corresponding schematic route of optical activation of GeNWs (Ren et al., 2007c).

Figure 3.3 shows the room temperature PL spectra of Er-GeNWs and Er:Yb-GeNWs. The same result with Figure 3.2(a) is shown in Figure 3.3(a) that few luminescence from the Er or Er:Yb codoped $\mathrm{SiO}_{2}-\mathrm{Al}_{2} \mathrm{O}_{3}$ without $\mathrm{GeNWs}$ was observed. But strong $\mathrm{Er}^{3+}$ luminescence (PL intensity is about 106.5 a.u.) at $1534 \mathrm{~nm}$ from Er-GeNWs is observed as shown in Figure 3.3(b), which is approximate two times higher than that of Er-SiNWs in Figure 3.2(b), indicating more energy transfer from carriers in GeNWs to $\mathrm{Er}^{3+}$ ions than that of in SiNWs. Furthermore, the PL intensity of $\mathrm{Er}^{3+}$ (about 343.6 a.u.) at $1532 \mathrm{~nm}$ from Er:Yb-GeNWs as shown in Figure 3.3(c) increased three times higher than that of only Er-GeNWs in Figure 3.3(b) after codoping $\mathrm{Yb}$ ions with Er ions, and a blue shift of the luminescence peak occurs as the $\mathrm{Yb}$ ions were added, suggesting that energy transfer from carriers in GeNWs to $\mathrm{Yb}$ ions and $\mathrm{Yb}$ ions are the sensitizer for the Er luminescence at $1534 \mathrm{~nm}$ after GeNWs participate in the luminescence excitation. 
The reasons of the PL distinction between Figure 3.2 and Figure 3.3 are deduced. One is perhaps due to the quantum effect of SiNWs and GeNWs. As shown in Figure 3.1, the diameter of the GeNWs is smaller than SiNWs. As we known, the optical properties of a quantum-confined system strongly depend on its size. Another reason is perhaps due to the indirect band gap nature of $\mathrm{Si}$ and Ge semiconductors. In Figure 3.2, photons are absorbed by the SiNWs and promote an electron from conduction band (CB) to the valence band (VB). Then the recombination of the electron with a hole in the valence band gives the typical Si nc light emission at $\sim 0.8 \mu \mathrm{m}$ (corresponding to $1.5 \mathrm{eV}$ ) (Khriachtchev \& Räsänen, 2005). Since the $1.5 \mathrm{eV}$ couples well with the ${ }^{4} I_{9 / 2}$ level of the Er manifold, in presence of Er, the energy can be transferred to the Er ions to excite it (Franzo` et al., 2000), as shown in Figure 3.4A ((a)-(e)). From this level, a rapid relaxation occurs to the ${ }^{4} I_{11 / 2}$ level with the subsequent emission of $0.98 \mu \mathrm{m}$ photons or with a relaxation to the metastable level ${ }^{4} I_{13 / 2}$ and emission of photons at $1534 \mathrm{~nm}$. For GeNWs, the recombination of the electrons with holes in the valence band gives the Ge nc light emission at the range of 0.9-2.3 eV (Kanemitsu et al., 1992; de Azevedo et al., 2005). Other wavelength besides $1.5 \mathrm{eV}$, such as $0.9 \mathrm{eV}$, could also couple well with the metastable ${ }^{4} I_{13 / 2}$ level of the Er manifold and emission of photons at $1534 \mathrm{~nm}$ (as shown in Figure 3.4B). These different wavelengths from GeNWs could excite more Er ions than single wavelength $(1.5 \mathrm{eV})$ from SiNWs. As a result, the PL intensity of Er-GeNWs is much higher than that of Er-SiNWs (as shown in Figure 3.2(b) and Figure 3.3(b)).

The optical properties of Er codoped with $\mathrm{Yb}$ further proved that the indirect gap nature of $\mathrm{Si}$ and Ge semiconductors decides the energy transfer between semiconductor and rare earth ions. If the nanowire diameter decides the optical property, the PL intensity of Er:YbSiNWs should improved than that of only Er-SiNWs due to the sensitizer of $\mathrm{Yb}$ to Er. Actually, the $\mathrm{Yb}$ ions have no any effects on the PL intensity of Er:Yb-SiNWs, because the 1.5 $\mathrm{eV}$ wavelengths from excited SiNWs cannot be absorbed by $\mathrm{Yb}$ ions, but only by Er ions. As a result, the $\mathrm{Yb}$ ions cannot be excited and the PL intensity of Er:Yb-SiNWs didn't change compared with that of Er-SiNWs after $\mathrm{Yb}$ ions doped with Er ions coating on the SiNWs surface.

However, the $\mathrm{Yb}$ ions have great effects on that of Er:Yb-GeNWs. GeNWs emit not only 0.9 $\mathrm{eV}$ and $1.5 \mathrm{eV}$ wavelengths to couple well with the metastable ${ }^{4} I_{13 / 2}$ level of the Er ions directly, but also $1.3 \mathrm{eV}$ wavelengths, coupling well with the excited state of $\mathrm{Yb}^{3+-2} F_{5 / 2}$ states. So the excited energy from $\mathrm{Yb}^{3+}$ can be transferred resonantly to the ${ }^{4} I_{11 / 2}$ level of $\mathrm{Er}^{3+}$. This excitation process is shown in Figure 3.4C. Moreover, Ge is well known to oxidize to form $\mathrm{GeO}$ and $\mathrm{GeO}_{2}$ in air on the GeNW surfaces (Tabet et al., 1999; Wang et al., 2004). These oxidations can be excited to emit a luminescence around $3.1-4.1 \mathrm{eV}$ (Oku et al., 2000). Theses lights cannot be absorbed by Er ions but can be absorbed by $\mathrm{Yb}$ ions (Kozanecki et al., 1999). As a result of photon absorption, the $\mathrm{Yb}$ ion becomes excited its $2+$ state, leaving a hole, $h_{\mathrm{VB}}$, in the valence band, which most probably is localized near $\mathrm{Yb}^{2+}$ ion. In the subsequent, $\mathrm{Yb}^{2+}+h_{\mathrm{VB}}$ recombination process $\mathrm{Yb}^{3+}$ is left in its excited ${ }^{2} \mathrm{~F}_{5 / 2}$ state, from which energy then can be transferred resonantly to the ${ }^{2} \mathrm{I}_{11 / 2}$ level of $\mathrm{Er}^{3+}$ (Song et al., 2006). Hence, the PL intensity of Er:Yb-GeNWs is the total intensities of the three processes and it is higher than that of without $\mathrm{Yb}$ codoping. The blue shift of the luminescence peak further indicates that $\mathrm{Yb}$ ions take part in the energy transfer during the optical activation of Er: $\mathrm{Yb}$ GeNWs. In summary, the optical activations of SiNWs and GeNWs are mainly dependent on the indirect gap nature of $\mathrm{Si}$ and Ge semiconductors. Stronger optical activation of Er:YbGeNWs is achieved. 

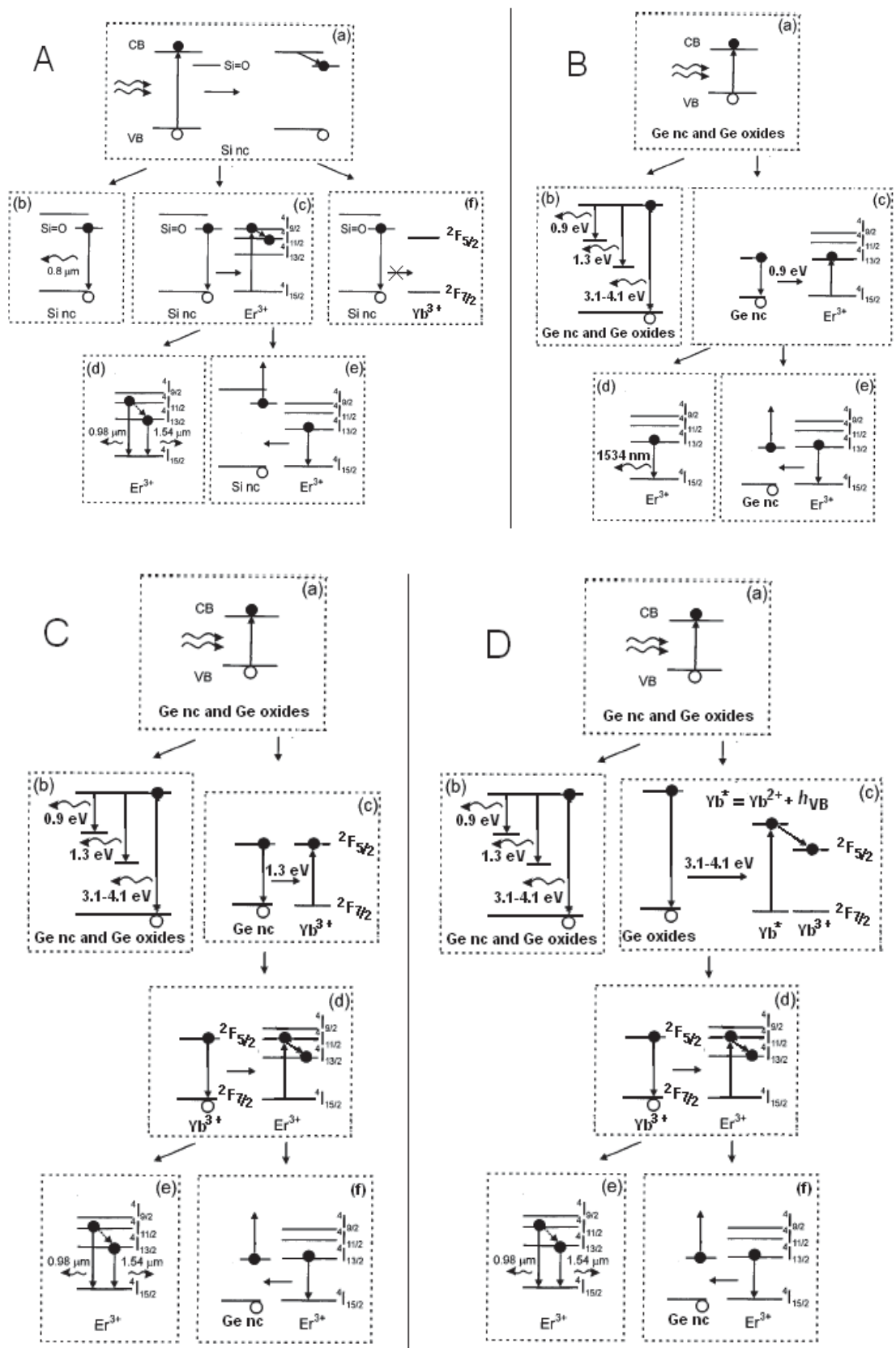

Fig. 3.4 Schematic of the mechanisms of optical activation of Er-doped and Er:Yb-codoped SiNWs and GeNWs. (A) Er-doped and Er:Yb-codoped SiNWs; (B) Er-doped GeNWs; (C) and (D) Er:Yb-codoped GeNWs (Ren et al., 2007c). 


\section{Conclusion}

Optical activations of Er doped Si ncs, SiNWs and GeNWs have been observed, but the PL intensity of $\mathrm{Si}$ ncs is weaker than those of SiNWs and GeNWs. So much progress has been made to improve the photoluminescence (PL) intensity; however, a challenging problem in Er-doped semiconductors is that only a small fraction of the excitation energy is transferred from ncs to Er ions. One of the major limitations is that isolated ncs cannot be efficiently addressed electrically. On this point, the successful optical activation of Er-doped SiNWs (Er-SiNWs) has been achieved. More important that the optimum location for $\mathrm{Er}^{3+}$ is not inside $\mathrm{Si}$, but in the nanometer-thin oxide shell right next to $\mathrm{Si}$. This gives us simple ways to dope the NWs with additional technologies, such as sol-gel method. Thus, this process avoids the fabrication of SiNWs with Er ions directly. The long length of SiNWs exceeding 1 $\mu \mathrm{m}$ overcomes the isolation of $\mathrm{Si}$ nc dispersed in the $\mathrm{SiO}_{2}$ and $\mathrm{Al}_{2} \mathrm{O}_{3}$ matrix to provide a very high areal density of Er ions. Moreover, the controlled growth of well-ordered Er-doped SiNWs has been achieved. The growth of patterned SiNWs, the doping of Er ions and the sintered process are completed in one step. The Er-doped aluminium gels are calcined to be powders when SiNWs are grown by a VLS mechanism, removing sintered process, so the energy consume is reduced. Similarly, the GeNWs posses the same result. Moreover, the rare earth $\mathrm{Yb}$ may improve the PL intensity of Er-doped GeNWs additionally.

In the future, the additional technologies for Er doping are required more attentions. For sol-gel method, the sol-gel film quality is important, such as no cracks, homogeneous, no concentration quench, and so on.The challenging researches focus on how to further improve the film quality and fine control of the film thickness to match well with the actual requirements. In addition, the SiNW diameter also has great affection on the PL intensity. The controlled growth of Er-doped SiNWs with stable diameter and arrays are also good challenge.

\section{Reference}

d'Acapito, F., Mobilio, S., Gastaldo, P., Barbier, D., Santos,Luis F., Martins, O. \& Almeida, R. M. J. Non-Cryst. Solids, Vol. 293-295, (2001). pp. (118-120).

Allen, J. E., Hemesath, E. R., Perea, D. E., Lensch-Falk, J. L., Li, Z. Y., Yin, F., Gass, M. H., Wang, P., Bleloch, A. L., Palmer, R. E. \& Lauhon, L. J. (2008). High-resolution detection of Au catalyst atoms in Si nanowires, Nat. Nanotechnol., Vol. 3, (Feb. 2008). pp. (168-173), ISSN: 1748-3387.

Amelinckx, S. Zhang, X. B. Bermaerts, D. Bernaerts, D. Zhang, X. F.;Ivanov, V. Nagy, J. B. (1994). A Formation Mechanism for Catalytically Grown Helix-Shaped Graphite Nanotubes, Science, Vol. 265, Issue 5172, (July 1994). pp. (635-639), ISSN: 0036-8075.

Andersen, S. E. S., Brenner, R., Wellard, C. J., Yang, C., Hopf, T., Escott, C. C., Clark, R. G., Dzurak, A. S., Jamieson, D. N. \& Hollenberg, C. L. (2007). Charge State Control and Relaxation in an Atomically Doped Silicon Device, Nano Lett., Vol. 7, Issue 7, (July 2007). pp. (2000-2003), ISSN: 1530-6984.

Armelao, L., Gross, S., Obetti, G., Tondello, E. (2005). Er ${ }^{3+}$-doped $\mathrm{SiO}_{2}-\mathrm{Al}_{2} \mathrm{O}_{3}$ thin films prepared by the sol-gel route, Surf. Coating Tech, Vol. 190, Issue 2-3, (2005). pp. (218-222), ISSN: 0257-8972. 
Azarian, A., Iraji Zad, A., Dolati, A. \& Mahdavi, S. M. (2009). Field emission of Co nanowires in polycarbonate template, Thin Solid Films, Vol. 517, Issue 5, (Jan. 2009). pp. (1736-1739), ISSN: 0040-6090.

de Azevedo, W.M., da Silva Jr, E.F., de Vasconcelos, E.A., Boudinov, H. (2005). Visible photoluminescence from $\mathrm{Ge}$ nanoclusters implanted in nanoporous aluminum oxide films, Microelectronics Journal, Vol. 36, Issue 11, (Nov. 2005). pp. (992-994), ISSN: 0026-2692.

Bogart, T. E., Dey, S., Lew, K.-K., Mohney, S. E. \& Redwing, J. M. (2005). Diameter-Controlled Synthesis of Silicon Nanowires Using Nanoporous Alumina Membranes, AdV. Mater., Vol. 17, Issue 1, (Jan. 2005). pp. (114-117), ISSN: 1521-4095.

Bootsma, G. A. \& Gassen, H. J. (1971). A quantitative study on the growth of silicon whiskers from silane and germanium whiskers from germane, J. Cryst. Growth, Vol. 10, Issue 3, (Aug. 1971). pp. (223-234), ISSN: 0022-0248.

Brus, L. (1994). Luminescence of Silicon Materials: Chains, Sheets, Nanocrystals, Nanowires, Microcrystals, and Porous Silicon, J. Phys. Chem., Vol. 98, Issue 14, (Apr. 1994). pp. (3575-3581).

Cassell, A. M., Verma, S., Delzeit, L., Meyyappan, M. \& Han, J. (2001). Combinatorial Optimization of Heterogeneous Catalysts Used in the Growth of Carbon Nanotubes, Langmuir, Vol. 17, Issue 2, (Jan. 2001). pp. (260-264), ISSN: 0743-7463.

Chryssou, C. E., Kenyon, A. J., Iwayama, T. S., Pitt, C. W. \& Hole, D. E. (1999). Evidence of energy coupling between Si nanocrystals and $\mathrm{Er}^{3+}$ in ion-implanted silica thin films, Appl. Phys. Lett., Vol. 75, Issue 14, (1999). pp. (2011-2014), ISSN: 0003-6951.

Chung, S. W., Yu, J. Y. \& Heath, J. R. (2000). Silicon nanowire devices, Appl. Phys. Lett., Vol. 76, Issue 15, (Apr. 2000). pp. (2068-2070), ISSN: 0003-6951.

Coffa, S., Franzo`,G., Priolo, F., Polman, A. \& Serna, R. Temperature dependence and quenching processes of the intra-4f luminescence of Er in crystalline Si. Phys. Rev., $B$, Vol. 49, Issue 23 (1994). pp. (16313-16320), ISSN: 1098-0121.

Cui, Y., Lauhon, L. J., Gudiksen, M. S., Wang, J. \& Lieber, C. M. (2001). Diameter-controlled synthesis of single-crystal silicon nanowires, Appl. Phys. Lett., Vol. 78, Issue 15, (Apr. 2001). pp. (2214-2216), ISSN: 0003-6951..

Dai, H. J., Wong, E. W., Lu, Y. Z., Fan, S. S. \& Lieber, C. M. (1995). Synthesis and characterization of carbide nanorods, Nature, Vol. 375, (June 1995). pp. (769-772), ISSN: 0028-0836.

Ennen, H., Schneider, J., Pomrenke, G. \& Axmann, A. (1983). 1.54- $\mu$ m luminescence of erbium-implanted III-V semiconductors and silicon, Appl. Phys. Lett., Vol. 43, Issue10, (1983). pp. (943-946), ISSN: 0003-6951.

Feofilov, S.P., Kulinkin, A.B., Kutsenko, A.B. \& Zakharchenya, R.I. (1998). Selective laser spectroscopy of $\mathrm{RE}^{3+}$ and $\mathrm{Mn}^{4+}$ in sol-gel technique produced $\mathrm{Al}_{2} \mathrm{O}_{3}$, Journal of Luminescence, Vol. 76\&77, (1998). pp. (217-220), ISSN: 0022-2313.

Franzo', G., Vinciguerra, V. \& Priolo, F. (1999). The excitation mechanism of rare-earth ions in silicon nanocrystals, Appl. Phys. A: Mater. Sci. Process., Vol. 69, Issue 1, (Jul. 1999). pp. (3-12), ISSN (printed): 0947-8396.

Franzo`, G., Pacifici, D., Vinciguerra, V., Priolo, F. \& Iacona, F. (2000). Er ${ }^{3+}$ ions-Si nanocrystals interactions and their effects on the luminescence properties. Appl. Phys. Lett., Vol. 76, Issue 16, (2000). pp. (2167-2179), ISSN: 0003-6951. 
Franzó, G., Irrera, A., Moreira, E. C., Miritello, M., Iacona, F., Sanfilippo, D., Di Stefano, G., Fallica, P. G. \& Priolo, F. (2002). Electroluminescence of silicon nanocrystals in MOS structures, Appl. Phys. A: Mater. Sci. Process., Vol.74, Issue 1, (Jan. 2002). pp. (1-5), ISSN (printed): 0947-8396.

Franzo`, G., Boninelli, S., Pacifici, D., Priolo, F., Iacona, F. \& Bongiorno, C. (2003). Sensitizing properties of amorphous Si clusters on the 1.54- $\mu \mathrm{m}$ luminescence of Er in Si-rich $\mathrm{SiO}_{2}$, Appl. Phys. Lett., Vol. 82, Issue 22 , (2003). pp. (3871-3875), ISSN: 0003-6951.

Fujii, M., Yoshida, M., Kanzawa, Y., Hayashi, S. \& Yamamoto, K. (1997). $1.54 \mu \mathrm{m}$ photoluminescence of $\mathrm{Er}^{3+}$ doped into $\mathrm{SiO}_{2}$ films containing $\mathrm{Si}$ nanocrystals: Evidence for energy transfer from Si nanocrystals to $\mathrm{Er}^{3+}$, Appl. Phys. Lett., Vol. 71, Issue 9, (1997). pp. (1198-1200) , ISSN: 0003-6951.

Fujii, M., Yoshida, M., Hayashi, S. \& Yamamoto, K. (1998). Photoluminescence from $\mathrm{SiO}_{2}$ films containing Si nanocrystals and Er: Effects of nanocrystalline size on the photoluminescence efficiency of $\mathrm{Er}^{3+}$, J. Appl. Phys., Vol. 84, Issue 8, (1998). pp. (4525-4531).

Gangloff, L., Minoux, E., Teo, K. B. K., Vincent, P., Semet, V., Binh, V. T., Yang, M. H., Lacerda, R. G., Bu, I. Y. Y., Pirio, G., Schnell, J. P., Pribat, D., Hasko, D. G., Amaratunga, G. A. J., Milne, W. I. \& Legagneux, P. (2004). Self-Aligned, Gated Arrays of Individual Nanotube and Nanowire Emitters, Nano Lett., Vol.4, Issue 9, (Sep. 2004). pp. (1575-1579), ISSN: 1530-6984.

Gao, T., Meng, G., Wang, Y., Sun, S. \& Zhang, L. (2002). Electrochemical synthesis of copper nanowires, J. Phys.: Condens. Matter, Vol. 14, Issue 3, (Jan. 2002). pp. (355-363), ISSN: 0953-8984.

Geiger, F., Busse, C. A. \& Loehrke, R. I. (1987). The vapor pressure of indium, silver, gallium, copper, tin, and gold between 0.1 and 3.0 bar, Int. J. Thermophys., Vol. 8, Issue 4, (1987). pp. (425-436), ISSN: 0195-928X.

Giovine, E., Notargiacomo, A., Di Gaspare, L., Palange, E., Evangelisti, F., Leoni, R., Castellano, G., Torrioli, G. \& Foglietti, V. (2001). Investigation of SiGeheterostructure nanowires, Nanotechnology, Vol. 12, Issue 2, (June 2001). pp. (132135), ISSN: 0957-4484.

Givargizov, E.I. (1975). Fundamental aspects of VLS growth, J. Crystal Growth, Vol. 31, (Dec. 1975). pp. (20-30), ISSN: 0022-0248.

Givargizov, E. I.; Sheftal, N. N. Morphology of silicon whiskers grown by the VLStechnique, J. Cryst. Growth, Vol. 9, (May 1971). pp. (326-329), ISSN: 0022-0248.

Gu, G., Burghard, M., Kim, G. T., Du“sberg, G. S., Chiu, P. W., Krstic, V., Roth, S. \& Han, W. Q. (2001). Growth and electrical transport of germanium nanowires, J. Appl. Phys., Vol. 90, Issue 11, (Dec. 2001). pp. (5747-5752), ISSN:0021-8979.

Han, H-S., Seo, S-Y., Shin, J. H. \& Park, N. (2002). Coefficient determination related to optical gain in erbium-doped silicon-rich silicon oxide waveguide amplifier. Appl. Phys. Lett., Vol. 81, Issue 20, (2002). pp. (3720-3722), ISSN: 0003-6951.

Han, W. Q., Fan, S. S., Li, Q. Q. \& Gu, B. L. (1997). Synthesis of silicon nitride nanorods using carbon nanotube as a template, Appl. Phys. Lett., Vol. 71, Issue 16, (Oct. 1997a). pp. (2271-2273), ISSN: 0003-6951. 
Han, W. Q., Fan, S. S., Li, Q. Q., Liang, W.J., Gu, B. L. \& Yu, D. P. (1997). Continuous synthesis and characterization of silicon carbide nanorods, Chem. Phys. Lett., Vol. 265, Issue 3-5, (Feb.1997b). pp. (374-378), ISSN: 0009-2614.

Han, W.Q., Bando, Y. Kurashima, K. \& Sato, T. Synthesis of boron nitride nanotubes from carbon nanotubes by a substitution reaction, Appl. Phys. Lett., Vol. 73, Issue 21, (Nov. 1998). pp. (3085-3087), ISSN: 0003-6951.

Han, W. Q., Philipp, K. R., Ernst, F. \& Ru“ hle, M. (1999). Formation of (BN)xCy and BN Nanotubes Filled with Boron Carbide Nanowires, Chem. Mater., Vol. 11, Issue 12, (Dec. 1999). pp. (3620-3623), ISSN: 0897-4756.

Hochbaum, A. I., Fan, R., He, R. \& Yang, P. (2005). Controlled Growth of Si Nanowire Arrays for Device Integration, Nano Lett., Vol. 5, Issue 3, (Mar. 2005). pp. (457-460), ISSN (printed): 1530-6984.

van den Hoven, G. N., Snoeks, E., Polman, A., van Uffelen, J. W. M., Oei,Y. S. \& Smit, M. K. (1993). Photoluminescence characterization of Er-implanted $\mathrm{Al}_{2} \mathrm{O}_{3}$ films, Appl. Phys. Lett., Vol. 62, Issue 24, (Jun 1993). pp. (3065-3067), ISSN: 0003-6951.

van den Hoven, G. N., Snoeks, E., Polman, A., van Dam, C., van Uffelen, J. W. M. \& Smit, M. K. (1996). Upconversion in Er-implanted $\mathrm{Al}_{2} \mathrm{O}_{3}$ waveguides, J. Appl. Phys., Vol. 79, Issue 3, (1996). pp. (1258-1266), ISSN: 0021-8979.

Huang, J., Chiam, S. Y., Tan, H. H., Wang, S. \& Chim W. K. Fabrication of Silicon Nanowires with Precise Diameter Control Using Metal Nanodot Arrays as a Hard Mask Blocking Material in Chemical Etching, Chem. Mater., Vol. 22, (2010). pp. (41114116), ISSN 0897-4756.

Huang, S. M., Mau, A. M. H., Turney, T. W., White, P. A. \& Dai, L. M. (2000). Patterned Growth of Well-Aligned Carbon Nanotubes: A Soft-Lithographic Approach, J. Phys. Chem. B, Vol. 104, Issue 10, (March 2000). pp. (2193-2196), ISSN: 1520-6106.

Iacona, F., Franzo', G. \& Spinella, C. (2000). Correlation between luminescence and structural properties of Si nanocrystals, J. Appl. Phys., Vol. 87, Issue 3, (Feb. 2000). pp. (1295-2303), ISSN: 0021-8979.

Iacona, F., Pacifici, D., Irrera, A., Miritello, M., Franzo` , G., Priolo, F., Sanfilippo, D., DiStefano, G. \& Fallica, P.G. (2002). Electroluminescence at $1.54 \mu \mathrm{m}$ in Er-doped Si nanocluster-based devices, Appl. Phys. Lett., Vol. 81, Issue 17 , (2002). pp. (32423244), ISSN: 0003-6951.

Irrera, A., Pacifici, D., Miritello, M., Franzó, G., Priolo, F., Iacona, F., Di Stefano, G. \& Fallica, P. G. (2002). Excitation and de-excitation properties of silicon quantum dots under electrical pumping, Appl. Phys. Lett., Vol. 81, Issue 10, (2002). pp. (1866-1868), ISSN: 0003-6951.

Islam, M., Sharma, S., Kamins, T. I. \& Williams, R. S. (2004). Ultrahigh-Density Semiconductor Nano-bridges Formed Between two Semiconductor Surfaces, Nanotechnology, Vol. 15, Issue 5 (May 2004). pp. (L5-L8), ISSN 0957-4484.

Jaymes, I., Douy, A., Massiot, D. \& Coutres, J. P. (1996). Evolution of the Si environment in mullite solid solution by 29Si MAS-NMR spectroscopy, J. Non-Cryst. Solids, Vol. 204, Issue 2, (1996). pp. (125-134), ISSN: 0022-3093.

Jimenez de Castro, M., Serna, R., Chaos, J. A., Afonso, C. N. \& Hodgson, E. R. (2000). Influence of defects on the photoluminescence of pulsed-laser deposited Er-doped amorphous $\mathrm{Al}_{2} \mathrm{O} 3$ films, Nucl. Instrum. Methods B, Vol. 166-167, (2000). pp. (793797), ISSN: 0168-583X. 
Kanemitsu, Y., Uto, H., Masumoto, Y. \& Maeda, Y. (1992). On the origin of visible photoluminescence in nanometer-size Ge crystallites, Appl. Phys. Lett., Vol. 61, Issue 18, (Nov. 1992). pp. (2187-2189), ISSN:0003-6951.

Kenyon, A. J., Trwoga, P. F., Federighi, M. \& Pitt, C. W. (1994). Optical properties of PECVD erbium-doped silicon-rich silica: evidence for energy transfer between silicon microclusters and erbium ions, J. Phys.: Condens. Matter, Vol. 6, Issue 21, (1994). pp. (L319), ISSN 0953-8984.

Kenyon, A. J., Chryssou, C. E. \& Pitt, C. W. (2000). Indirect excitation of $1.5 \mu \mathrm{m}$ emission from Er3+ in silicon-rich silica, Appl. Phys. Lett., Vol. 76, Issue 6, (2000). pp. (688690), ISSN: 0003-6951.

Kenyon, A. J. (2002). Recent developments in rare-earth doped materials for optoelectronics, Progress in Quantum Electronics, Vol. 26, Issue 4-5, (2002). pp. (225-284), ISSN: 0079672).

Khanal, D. R., Yim, J. W. L., Walukiewicz, W. \& Wu, J. (2007). Effects of Quantum Confinement on the Doping Limit of Semiconductor Nanowires, Nano Lett., Vol. 7, Issue 5, (May 2007). pp. (1186 -1190), ISSN: 1530-6984.

Khriachtchev, L. \& Räsänen, M. (2005). Free-standing silica film containing Si nanocrystals: Photoluminescence, Raman scattering, optical waveguiding, and laser-induced thermal effects, Appl. Phys. Lett., Vol. 86, Issue 14, (Apr. 2005). pp. (141911-141913), ISSN:0003-6951.

Kik, P. G., Brongersma, M. L. \& Polman, A. (2000). Strong exciton-erbium coupling in Si nanocrystal-doped $\mathrm{SiO}_{2}$, Appl. Phys. Lett., Vol. 76, Issue 17, (2000). pp. (2325-2327), ISSN: 0003-6951.

Kim, C. S., Chung, Y. B., Youn, W. K. \& Hwang, N. M. (2009). Generation of charged nanoparticles during the synthesis of carbon nanotubes by chemical vapor deposition, Carbon, Vol. 47, Issue 10, (Aug. 2009b). pp. (2511-2518), ISSN: 0008-6223.

Kim, C. S., Kwak, I. J., Choi, K. J., Park, J. G. \& Hwang, N. M. (2010). Generation of Charged Nanoparticles During the Synthesis of Silicon Nanowires by Chemical Vapor Deposition, J. Phys. Chem. C, Vol. 114, Issue 8, (Mar. 2010). pp. (3390- 3395), ISSN: $1932-7447$.

Kimura, T., Isshiki, H., Ide, S., Shimizu, T. \& Ishida, T. (2003). Suppression of Auger deexcitation and temperature quenching of the Er-related $1.54 \mu \mathrm{m}$ emission with an ultrathin oxide interlayer in an $\mathrm{Er} / \mathrm{SiO}_{2} / \mathrm{Si}$ structure, J. Appl. Phys., Vol. 93, Issue 5, (2003). pp. (2595-2601), ISSN:0021-8979.

Kind, H., Bonard, J., Forro, L., Nilsson, L. \& Schlapbach, L. (2000). Printing Gel-like Catalysts for the Directed Growth of Multiwall Carbon Nanotubes, Langmuir, Vol. 16, Issue 17, (August 2000). pp. (6877-6883), ISSN: 0743-7463.

Klimov, V. I., Schwarz, C., McBranch, D. \& White, C. W. (1998). Initial carrier relaxation dynamics in ion-implanted Si nanocrystals: Femtosecond transient absorption study, Appl. Phys. Lett., Vol. 73, Issue 18, (Nov. 1998). pp. (2603-2605), ISSN: 0003-6951.

Kozanecki, A., Homewood, K. \& Sealy, B. J. J. Appl. Phys., Vol. 75, (1999). pp. (793-795).

Kozanecki, A., Sealy, B.J., Homewood, K., Ledain, S., Jantsch, W. \& Kuritsyn, D. (2001). Sensitization of the $1.54 \mu \mathrm{m}$ luminescence of $\mathrm{Er} 3+$ in $\mathrm{SiO}_{2}$ films by $\mathrm{Yb}$ and Sinanocrystals. Materials Science and Engineering B, Vol. 81, Issue 1-3, (Apr. 2001). pp. (23-28). ISSN: 0921-5107. 
Krishnan, R. \& Thompson, C. V. (2007). Monodomain High-Aspect-Ratio 2D and 3D Ordered Porous Alumina Structures with Independently Controlled Pore Spacing and Diameter, Adv. Mater., Vol. 19, Issue 7, (Apr. 2007). pp. (988-992), ISSN: 15214095.

Lew, K. K. \& Redwing, J. M. (2003). Growth characteristics of silicon nanowires synthesized by vapor-liquid-solid growth in nanoporous alumina templates, J. Cryst. Growth, Vol. 254, Issue 1-2, (June 2003). pp. (14-22), ISSN: 0022-0248.

Linnros, J., Lalic, N., Galeckas, A. \& Grivickas, V. (1999). Analysis of the stretched exponential photoluminescence decay from nanometer-sized silicon crystals in $\mathrm{SiO}_{2}$, J. Appl. Phys., Vol. 86, Issue 11, (1999). pp. (6128-6134), ISSN: 0021-8979.

Lombardi, I., Hochbaum, A. I., Yang, P., Carraro, C. \& Maboudian, R. (2006). Synthesis of High Density, Size-Controlled Si Nanowire Arrays via Porous Anodic Alumina Mask, Chem. Mater., Vol. 18, Issue 4, (Feb. 2006). pp. (988-991), ISSN: 0897-4756.

Moore, G. E. Electronics, Vol. 38, (1965). pp. (84-90).

Mandl, B., Stangl, J., Hilner, E., Zakharov, A. A., Hillerich, K., Dey, A. W., Samuelson, L., Bauer, G., Deppert, K. \& Mikkelsen, A. (2010). Growth Mechanism of SelfCatalyzed Group III-V Nanowires, Nano Lett., Vol. 10 Issue 11, (Dec. 2010). pp. (4443-4449), ISSN (printed): 1530-6984.

Masuda, H. \& Fukuda, K. (1995). Ordered Metal Nanohole Arrays Made by a Two-Step Replication of Honeycomb Structures of Anodic Alumina, Science, Vol. 268, Issue 5216, (Jun. 1995). pp. (1466-1468), ISSN 0036-8075 (print).

Morales, A. M. \& Lieber, C. M. (1998). A Laser Ablation Method for the Synthesis of Crystalline Semiconductor Nanowires, Science, Vol. 279, Issue 5348, (Jan. 1998). pp. (208-211), ISSN 0036-8075 (print).

Nielsch, K., Mu“" ller, F., Li, A.-P. \& Go“" sele, U. (2000). Uniform Nickel Deposition into Ordered Alumina Pores by Pulsed Electrodeposition, Adv. Mater., Vol. 12, Issue 8, (Apr. 2000). pp. (582-586), ISSN: 1616-301X (Print).

Nielsch, K., Choi, J., Schwirn, K., Wehrspohn, R. B. \& Gosele, U. (2002). Self-ordering Regimes of Porous Alumina: The 10 Porosity Rule, Nano Lett., Vol. 2, Issue 7, (Jul. 2002). pp. (677-680), ISSN (printed): 1530-6984.

Nishio, K., Koga, J., Yamaguchi, T. \& Yonezawa, F. (2003). Theoretical study of lightemission properties of amorphous silicon quantum dots, Phys. Rev. B, Vol. 67, Issue 19, (2003). pp. (195304-195308), ISSN: 1098-0121,).

Oku, T., Nakayama, T., Kuno, M., Nozue, Y., Wallenberg, L. R., Niihara, K. \& Suganuma, K. (2000). Formation and photoluminescence of Ge and Si nanoparticles encapsulated in oxide layers, Materials Science and Engineering B, Vol. 74, Issue 1-3, (May 2000). pp. (242-247), ISSN: 0921-5107.

Osada, Y., Nakayama, H., Shindo, M., Odaka, T. \& Ogata, Y. (1979). Growth and Structure of Silicon Fibers, J, Electrochem. Soc., Vol. 126, Issue 1, (Jan. 1979). pp. (31-36), ISSN: 0013-4651 (print).

Pan, A. W., Dai, S. \& Lowndes, D. H. (2005). Straight single-crystalline germanium nanowires and their patterns grown on sol-gel prepared gold/silica substrates, Solid State Communications, Vol. 134, Issue 4, (April 2005). pp. (251-255), ISSN: 0038-1098.

Park, N.-M., Kim, T.-Y., Kim, S. H., Sung, G. Y., Cho, K. S., Shin, J. H., Kim, B.-H., Park, S.-J., Lee, J.-K. \& Nastasi, M. (2005). Luminescence of Er-doped amorphous silicon quantum dots, Thin Solid Films Vol. 475, (2005). pp. (231- 234), ISSN: 0040-6090. 
Patra, A. (2004). Study of photoluminescence properties of Er3+ ions in $\mathrm{SiO}_{2}-\mathrm{GeO}_{2}$ and $\mathrm{Al}_{2} \mathrm{O}_{3}$ nanoparticles, Solid State Communications, Vol. 132, Issue 5, (2004). pp. (299303), ISSN: 0038-1098.

Pavesi, L. (1996). Influence of dispersive exciton motion on the recombination dynamics in porous silicon, J. Appl. Phys., Vol. 80, Issue 1, (1996). pp. (216-225), ISSN: 0021-8979.

Perea, D. E., Allen, J. E., May, S. J., Wessels, B. W., Seidman, D. N. \& Lauhon, L. J. (2006). Three-Dimensional Nanoscale Composition Mapping of Semiconductor Nanowires, Nano Lett., Vol. 6, Issue 2, (Feb. 2006). pp. (181-185), ISSN (printed): 1530-6984.

Petkov, N., Platschek, B., Morris, M. A., Holmes, J. D. \& Bein, T. (2007). Oriented Growth of Metal and Semiconductor Nanostructures within Aligned Mesoporous Channels, Chem. Mater., Vol. 19, Issue 6, (Mar. 2007). pp. (1376-1381), ISSN 0897-4756 (print).

Polman, A., Jacobson, D. C., Eaglesham, D. J., Kiatler, R. C. \& Poate, J. M. J. Appl. Phys. Vol. 70, (1991). pp. (3778-3781).

Polman, A. Erbium implanted thin film photonic materials. (1997). J. Appl. Phys., Vol. 82, Issue 1, (1997). pp. (1-39), ISSN: 0021-8979.

Priolo, F., Franzo, G., Pacifici, D. \& Vinciguerra, V. (2001). Role of the energy transfer in the optical properties of undoped and Er-doped interacting Si nanocrystals, J. Appl. Phys., Vol. 89, Issue 1, (Jan. 2001). pp. (264-272), ISSN: 0021-8979.

Ren, L. (2008). Optical Activation of Si Nanowires Coating with Er-Doped SiO2 and Al2O3 Derived from Sol-Gel Solutions, Journal of Nanoelectronics and Optoelectronics, Vol. 3, Issue 2, (Jul. 2008). pp. (190-194), ISSN: 1555-130X (Print).

Ren, L., Jeung, W. Y., Han, H. C., Suh, K. Shin, J. H. \& Choi, H. J. (2007a). Optical activation of $\mathrm{Si}$ nanowires by Er3+ doped binary $\mathrm{Si}-\mathrm{Al}$ oxides films derived from sol-gel solutions, Optical Materials, Vol. 30, Issue 3, (Nov. 2007a). pp. (497-501), ISSN: 0925-3467.

Ren, L., Jeung, W. Y. \& Choi, H. J. (2007b). Optical activation of patterned Si nanowires grown from sol-gel prepared gold/Er-doped aluminous film, Applied Surface Science, Vol. 253, Issue 22, (Sep. 2007b). pp. (8885-8888), ISSN: 0169-4332.

Ren, L. Jeung, W. Y. Han, H. C. \& Choi, H. J. (2007c). Optical Activation of Si and Ge Nanowires Codoping with Er:Yb Rare Earth by Sol-Gel Methods, Journal of Nanoelectronics and Optoelectronics, Vol. 2, Issue 2, (Agu. 2007c). pp. (191-196) , ISSN: 1555-130X (Print).

Ryu, C. K. \& Kim, K. (1995). Fabrication of highly concentrated Er3+ doped aluminosilicate films via sol-gel processing. Appl. Phys. Lett., Vol. 66, Issue 19, (May 1995). pp. (2496-2498), ISSN:0003-6951.

Schmidt, M., Heitmann, J., Scholz, R. \& M. Zacharias, (2002). Bright luminescence from erbium doped nc-Si/ $\mathrm{SiO}_{2}$ superlattices. J. Non-Cryst. Solids, Vol. 299-302, Part 1, (Jan. 2002). pp. (678-682), (ISSN: 0022-3093).

Schmidt, V.; Senz, S.; Go“sele, U., (2005). UHV chemical vapour deposition of silicon nanowires, Zeitschrift für Metallkunde, Vol. 96, No. 5, (2005). pp. (427-428), ISSN: 0044-3093.

Schmidt, V, Wittemann, J. V. \& Go“sele, U. (2010). Growth, Thermodynamics, and Electrical Properties of Silicon Nanowires, Chem. Rev., Vol. 110, Issue 1, (Jan. 2010). pp. (361388), ISSN: 0009-2665 (print).

Shchetinin, A. A., Nebol'sin, V. A., Kozenkov, O. D., Tatarenkov, A. F. \& Dunaev, A. I. N. E. P. (1991). Further studies on the role of neighboring group participation in carbonyl 
substitution reactions of group 6 metal carboxylates, Inorg. Mater., Vol. 30, ISSUE 5, (Mar.1991). pp. (1137-1142), ISSN: 0020-1669 (print).

Seo, S.-Y. \& Shin, J. H. Exciton-erbium coupling and the excitation dynamics of Er3+ in erbium-doped silicon-rich silicon oxide, Appl. Phys. Lett., Vol. 78, Issue18, (2001). pp. (2709-2712). (ISSN:0003-6951).

Solak, H. H. (2006). Nanolithography with coherent extreme ultraviolet light, J. Phys. D: Appl. Phys., Vol. 39, Issue 9, (May 2006). pp. (R171-R171), ISSN 0022-3727 (Print).

Shin, J. H., Kim, M-J., Seo, S-Y. \& Lee, C. (1998). Composition dependence of room temperature $1.54 \mu \mathrm{m} \mathrm{Er}{ }^{3+}$ luminescence from erbium-doped silicon:oxygen thin films deposited by electron cyclotron resonance plasma enhanced chemical vapor deposition. Appl. Phys. Lett., Vol. 72, Issue 9, (1998). pp. (1092-1094), ISSN: 0003-695).

Shin, J. H., Seo, S.-Y., Kim, S. \& Bishop, S. G. (2000). Photoluminescence excitation spectroscopy of erbium-doped silicon-rich silicon oxide. Appl. Phys. Lett., Vol. 76, Issue 15, (2000). pp. (1999-2001), ISSN: 0003-6951.

Shin, J. H., Jhe, J-H., Seo, S-Y., Ha, Y. H. \& Moon, D. W. (2000). Er-carrier interaction and its effects on the Er3+ luminescence of erbium-doped $\mathrm{Si} / \mathrm{SiO}_{2}$ superlattices, Appl. Phys.Lett., Vol. 76, Issue 24, (Jun 2000). pp. (3567-3569), ISSN: 0003-6951.

Snoeks, E., Lagendijk, A. \& Polman, A. (1995). Measuring and Modifying the Spontaneous Emission Rate of Erbium near an Interface, Phys. Rev. Lett., Vol. 74, Issue 13, (1995). pp. (2459-2462), ISSN:0031-9007.

Snoeks, E., van den Hoven, G. N., Polman, A., Hendriksen, B., Diemeer, M. B. J. \& Priolo, F. (1997). Cooperative upconversion in erbium-implanted soda-lime silicate glass optical waveguides, J. Opt. Soc. Am. B, Vol. 12, Issue 8, (1997). pp. (1468-1474), ISSN: 0740-3224.

Song, H. \& Bao, X. (1997). Visible photoluminescence from silicon-ion-implanted $\mathrm{SiO}_{2}$ sfilm and its multiple mechanisms, Phys. Rev. B, Vol. 55, Issue 11, (Mar. 1997). pp. (69886993), ISSN: 1098-0121.

Song, Q., Li, C.-R., Li, J.-Y., Ding, W.-Y., Li, S.-F., Xu, J., Deng, X.-L. \& Song, C.-L. (2006). Photoluminescence properties of the $\mathrm{Yb}$ :Er co-doped $\mathrm{Al}_{2} \mathrm{O}_{3}$ thin film fabricated by microwave ECR plasma source enhanced RF magnetron sputtering, Optical Materials, Vol. 28, Issue 12, (Sep. 2006). pp. (1344-1349), ISSN: 0925-3467.

Sood, D. K., Sekhar, P. K. \& Bhansali, S. (2006). Ion implantation based selective synthesis of silica nanowires on silicon wafers, Appl. Phys. Lett., Vol. 88, Issue 14, (Apr. 2006). pp. (143110-143112), ISSN: 0003-6951.

Stepikhova, M., Jantsch, W., Kocher, G., Palmetshofer, L., Shoisswohl, M. \& Von Bardeleben, H. J. (1997). Direct excitation spectroscopy of Er centers in porous silicon, Appl. Phys.Lett., Vol. 71, Issue 20, (Nov 1997). pp. (2975-2977), ISSN:0003-6951.

Stepikhova, M. V., Cerqueira, M. F., Losurdo, M., Giangregorio, M. M., Alves, E., Monteiro, T. \& Soares, M. J. Phys. Solid State, Vol. 46, (2004). pp. (113-116), ISSN: 1063-7834.

Suh, K., Shin, J. H., Park, O.-H., Bae, B.-S., Lee, J.-C. \& Choi, H.-J. (2005). Optical activation of Si nanowires using Er-doped, sol-gel derived silica, Appl. Phys. Lett., Vol. 86, (2005). pp. (053101-1 - 053101-3), ISSN 0003-6951.

Tabet, N., Al-Sadah, J. \& Salim, M. (1999). Growth of oxide layer on germanium (011) substrate under dry and wet atmospheres, Surf. ReV. Lett., Vol. 6, Issue 6, (Dec. 1999). pp. (1053-1060), ISSN: 0218-625X. 
Tanner, P.A., Wong, K.L. \& Liang, Y. (2004). Multiple phase production on doping $\mathrm{Er}^{3+}$ into a$\mathrm{Al}_{2} \mathrm{O}_{3}$, Chem. Phys. Lett., Vol. 399, Issue 1-3, (Nov. 2004). pp. (15-18), ISSN: 0009-2614.

Thess, A., Lee, R., Nikolaev, P., Dai, H., Petit, P., Robert, J., Xu, C., Lee, Y. H., Kim, S. G., Rinzier, A. G., Colbert, D. T., Scuseria, G. E., Tomanek, D., Fischer, J. E. \& Smalley, R. E. (1996). Crystalline Ropes of Metallic Carbon Nanotubes, Science, Vol. 273, issue 5274, (Jul. 1996). pp. (483-487), ISSN 0036-8075 (print).

Tilke, A. T., Simmel, F. C., Lorenz, H., Blick, R. H. \& Kotthaus, J. P. (2003). Quantum interference in a one-dimensional silicon nanowire, Phys. Rev., B, Vol. 68, Issue 7, (Agu. 2003). pp. (075311-1 - 075311-6), ISSN 1050-2947 (Print).

Treuting, R. G. \& Arnold, S. M. (1957). Orientation habits of metal whiskers, Acta Met., Vol. 5, Issue 10, (Oct. 1957). pp. (598-598), ISSN: 0412-1961.

Wang, D. \& Dai, H. (2002). Low-Temperature Synthesis of Single-Crystal Germanium Nanowires by Chemical Vapor Deposition, Angew. Chem. Int. Ed., Vol. 41, Issue 24, (Dec. 2002). pp. (4783-4786), ISSN:1521-3773.

Wang, D., Chang, Y.-L., Wang, Q., Cao, J., Farmer, D. B., Gordon, R. G. \& H. Dai, (2004). Surface Chemistry and Electrical Properties of Germanium Nanowires, J. Am. Chem. Soc., Vol. 126, Issue 37, (Sep. 2004). pp. (11602-11611), ISSN: 0002-7863.

Wang, F., Dong, A., Sun, J., Tang, R., Yu, H. \& Buhro, W. E. (2006). Solution-Liquid-Solid Growth of Semiconductor Nanowires, Inorg. Chem., Vol. 45, Issue 19, (Sep. 2006). pp. (7511-7521), ISSN 0020-1669 (printable version).

Wang, X. J., Lei, M. K., Yang, T. \& Wang, H. (2004). Phase structure and photoluminescence properties of $\mathrm{Er}^{3+}$-doped $\mathrm{Al}_{2} \mathrm{O}_{3}$ powders prepared by the sol-gel method, Opt. Mater., Vol. 26, Issue 3, (2004). pp. (247-252), ISSN: 0925-3467.

Wang, X. J., Lei, M. K., Yang, T. \& Cao, B. S. (2004). Coherent effect of $\mathrm{Er}^{3+}-\mathrm{Yb}^{3+}$ co-doping on enhanced photoluminescence properties of $\mathrm{Al}_{2} \mathrm{O}_{3}$ powders by the sol-gel method, Opt. Mater., Vol. 26, Issue 3, (2004). pp. (253-259), ISSN: 0925-3467.

Wang, X. J. \& Lei, M. K. (2005). Preparation and photoluminescence of $\mathrm{Er}^{3+}$-doped $\mathrm{Al}_{2} \mathrm{O}_{3}$ films by sol-gel method, Thin Solid Films, Vol. 476, Issue 1, (2005). pp. (41-45), ISSN: 0040-6090.

Wang, Z. \& Coffer, J. L. (2002). Erbium Surface-Enriched Silicon Nanowires, Nano Lett., Vol. 2, No. 11, (2002). pp. (1303-1305), ISSN (printed): 1530-6984.

Weber, L. (2002). Equilibrium solid solubility of silicon in silver, Metall. Mater. Trans. A, Vol. 33, Issue 4, (Apr. 2002). pp. (1145-1150), ISSN: 1073-5623 (print version).

Wolkin, M. V., Jorne, J., Fauchet, P. M., Allan, G. \& Delerue, C. (1999). Electronic States and Luminescence in Porous Silicon Quantum Dots: The Role of Oxygen, Phys. Rev. Lett., Vol. 82, Issue 1, (1999). pp. (197-200), ISSN: 0031-9007.

Wu, X., Kulkarni, J. S., Collins, G., Petkov, N., Alme'cija, D. Boland, J. J., Erts, D. \& Holmes J. D. (2008). Synthesis and Electrical and Mechanical Properties of Silicon and Germanium Nanowires, Chem. Mater., Vol. 20,Issue 19, (Oct. 2008). pp. (59545967), ISSN 0897-4756.

Wu, Y. \& Yang, P. (2001). Direct Observation of Vapor-Liquid-Solid Nanowire Growth, J. Am. Chem. Soc., Vol. 123, Issue 13, (Apr. 2001). pp. (3165-3166), ISSN 0002-7863.

Wu, Y., Cui, Y., Huynh, L., Barrelet, C. J., Bell, D. C. \& Lieber, C. M. (2004). Controlled Growth and Structures of Molecular-Scale Silicon Nanowires, Nano Lett., Vol. 4, Issue 3, (Feb. 2004). pp. (433-436) , ISSN (printed): 1530-6984. 
Xiang, Y., Lee, W., Nielsch, K., Abstreiter, G. \& Fontcuberta i Morral, A. (2008). Microstructured horizontal alumina pore arrays as growth templates for large area few and single nanowire devices, Phys. Status Solidi RRL, Vol. 2, Issue 2, (Jan. 2008). pp. (59-61), ISSN: 1862-6270.

Xiang, Y., Keilbach, A., Codinachs, Lia M., Nielsch, K., Abstreiter, G., Fontcuberta i Morral, A. \& Bein, T. (2010). Multiple Nanowire Species Synthesized on a Single Chip by Selectively Addressable Horizontal Nanochannels, Nano Lett., Vol. 10, (Mar. 2010). pp. (1341-1346), ISSN (printed): 1530-6984.

Yu, D. P., Lee, C. S., Bello, I., Sun, X. S., Tang, Y. H., Zhou, G. W., Bai, Z. G., Zhang, Z. \& Feng, S. Q. (1998). Synthesis of nano-scale silicon wires by excimer laser ablation at high temperature, Solid State Commun., Vol. 105, Issue 6, (Feb. 1998a). pp. (403-407), ISSN: 0038-1098.

Yu, D. P., Bai, Z. G., Ding, Y., Hang, Q. L., Zhang, H. Z., Wang, J. J., Zou, Y. H., Qian, W., Xiong, G. C., Zhou, H. T. \& Feng, S.Q. Nanoscale silicon wires synthesized using simple physical evaporation, Appl. Phys. Lett., Vol. 72, Issue 26, (Apr. 1998b). pp. (3458-3460), ISSN 0003-6951 (print).

Yu, J. Y., Chung, S. W. \& Heath, J. R. (2000). Silicon Nanowires: Preparation, Device Fabrication, and Transport Properties, J. Phys. Chem. B, Vol. 104, (Nov. 2000). pp. (11864-11870), ISSN 1089-5647.

Yudasaka, M., Komatsu, T., Ichihashi, T. \& Iijima, S. (1997). Single-wall carbon nanotube formation by laser ablation using double-targets of carbon and metal, Chem. Phys. Lett., Vol. 278, No. 1-3, (Oct. 1997). pp. (102-106), ISSN: 0009-2614.

Zhang, H. Z., Kong, Y. C., Wang,Y. Z., Du, X., Bai, Z. G., Wang, J. J., Yu, D. P., Ding, Y., Hang, Q. L. \& Feng, S. Q. (1999). $\mathrm{Ga}_{2} \mathrm{O}_{3}$ nanowires prepared by physical evaporation, Solid State Commun., Vol. 109, No. 11, (Mar. 1999). pp. (677-680), ISSN: 0038-1098.

Zhang, Y. F., Tang,Y. H., Lam C., Wang, N., Lee, C. S., Bello, I. \& Lee, S. T. (2000). Bulkquantity $\mathrm{Si}$ nanowires synthesized by $\mathrm{SiO}$ sublimation, J. Cryst. Growth, Vol. 212, No. 1-2, (Apr. 2000). pp. (115-118), ISSN: 0022-0248.

Zhang, Y. J., Zhu, J., Zhang, Q., Yan, Y. J., Wang, N. L. \& Zhang, X. (2000). Synthesis of $\mathrm{GeO}_{2}$ nanorods by carbon nanotubes template, Chem. Phys. Lett., Vol. 317, No. 3-5, (Feb. 2000). pp. (504-509), ISSN: 0009-2614.

Zhang, Y. J., Liu, J., He, R. R., Zhang, Q., Zhang, X. \& Zhu, J. (2001). Synthesis of Aluminum Nitride Nanowires from Carbon Nanotubes, Chem. Mater., Vol. 13, No. 11, (Sep. 2001). pp. (3899-3905), ISSN 0897-4756.

Zhang, X.-Y., Zhang, L.-D., Meng, G.-W., Li, G.-H., Phillip, N.-Y. J. \& Phillip, F. (2001). Synthesis of Ordered Single Crystal Silicon Nanowire Arrays, AdV. Mater., Vol. 13, No. 16, (Aug. 2001). pp. (1238-1241), ISSN: 1521-4095. 


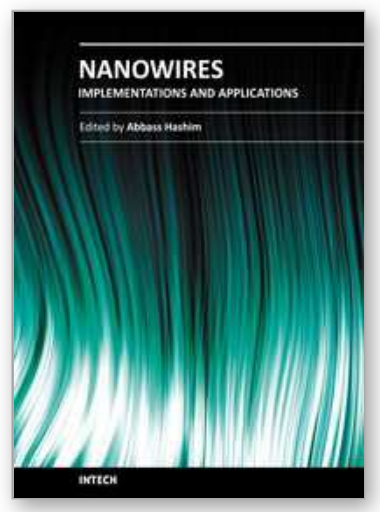

\author{
Nanowires - Implementations and Applications \\ Edited by Dr. Abbass Hashim
}

ISBN 978-953-307-318-7

Hard cover, 538 pages

Publisher InTech

Published online 18, July, 2011

Published in print edition July, 2011

This potentially unique work offers various approaches on the implementation of nanowires. As it is widely known, nanotechnology presents the control of matter at the nanoscale and nanodimensions within few nanometers, whereas this exclusive phenomenon enables us to determine novel applications. This book presents an overview of recent and current nanowire application and implementation research worldwide. We examine methods of nanowire synthesis, types of materials used, and applications associated with nanowire research. Wide surveys of global activities in nanowire research are presented, as well.

\title{
How to reference
}

In order to correctly reference this scholarly work, feel free to copy and paste the following:

Lingling Ren, Hongmei Li and Liandi Ma (2011). The Selective Growth of Silicon Nanowires and Their Optical Activation, Nanowires - Implementations and Applications, Dr. Abbass Hashim (Ed.), ISBN: 978-953-307-3187, InTech, Available from: http://www.intechopen.com/books/nanowires-implementations-and-applications/theselective-growth-of-silicon-nanowires-and-their-optical-activation

\section{INTECH}

open science | open minds

\section{InTech Europe}

University Campus STeP Ri

Slavka Krautzeka 83/A

51000 Rijeka, Croatia

Phone: +385 (51) 770447

Fax: +385 (51) 686166

www.intechopen.com

\section{InTech China}

Unit 405, Office Block, Hotel Equatorial Shanghai

No.65, Yan An Road (West), Shanghai, 200040, China

中国上海市延安西路 65 号上海国际贵都大饭店办公楼 405 单元

Phone: +86-21-62489820

Fax: +86-21-62489821 
(C) 2011 The Author(s). Licensee IntechOpen. This chapter is distributed under the terms of the Creative Commons Attribution-NonCommercialShareAlike-3.0 License, which permits use, distribution and reproduction for non-commercial purposes, provided the original is properly cited and derivative works building on this content are distributed under the same license. 